\title{
UM ESTUDO MULTINÍVEL SOBRE AS FILAS PARA INTERNAÇÕES RELACIONADAS COM A GRAVIDEZ, O PARTO E O PUERPÉRIO NO SUS
}

\author{
Alexandre Marinho ${ }^{\S}$ \\ Simone de Souza Cardoso
}

\begin{abstract}
RESUMO
Avaliamos os tempos de espera no Sistema Único de Saúde Brasileiro - SUS, para as internações relacionadas com o capítulo XV (gravidez, parto e puerpério) da CID-10 para os anos de 1999 e 2002. Primeiramente, estimamos os tempos de espera para atendimento com o auxílio de modelos de teoria das filas. Os tempos de espera são longos e elásticos em relação às taxas de chegada e às taxas de atendimento no SUS, e variam muito entre municípios e entre Estados. A seguir, estimamos, em modelos econométricos do tipo multinível, que o baixo peso ao nascer, as cesarianas, a taxa de fertilidade, o IDH e a importação de pacientes não residentes são positivamente correlacionados com os tempos de espera nas filas. Os exames do tipo pré-natal, a quantidade de enfermeiros e o gasto total per capita em saúde são negativamente correlacionados com esses tempos de espera.
\end{abstract}

Palavras-chave: gravidez, parto e puerpério, filas de espera, Sistema Único de Saúde - SUS.

\begin{abstract}
We study the waiting times for pregnancy, childbirth and puerperal care in the years of 1999 and 2002 within the Brazilian National Health System - SUS. The average waiting times were estimated by queueing theory models, and they were found to be very long and highly elastic, with respect to arrival and service rates in the system. The waiting times also presented great variability across municipalities and across states. By using multilevel regression models we estimate that the frequency of low birthweight; the cesarian section rates; the total fertility rate; the Human Development Index - IDH; and the proportion of non-resident cases treated are positively associated with waiting times. On the contrary, the utilization of prenatal care; the rates of nurses with higher level of education available; and the per capita total expenditure on health are negatively associated with waiting times.
\end{abstract}

Key words: pregnancy, childbirth and puerperal care, waiting times, Sistema Único de Saúde - SUS.

JEL Classification: C23, C44, I18.

\footnotetext{
* Agradecemos a dois pareceristas anônimos por comentários que ajudaram a enriquecer o texto.

$\S$ Do Instituto de Pesquisa Econômica Aplicada - IPEA, da Universidade do Estado do Rio de Janeiro - UERJ. E-mail: amarinho@ipea.gov.br.

a Assistente de Pesquisa no IPEA. E-mail: simonesc@ipea.gov.br.

Endereço para contato: Av. Presidente Antonio Carlos, 51, décimo andar, Rio de Janeiro, RJ. CEP: 20.020-010.
}

Recebido em dezembro de 2005. Aceito para publicação em dezembro 2007. 


\section{INTRODUÇÃo}

O atendimento às gestantes, parturientes, puérperas e recém-nascidos é um problema central em sistemas de saúde em todo o mundo (WHO, 2005). No Brasil (que não é exceção à regra), no ano de 2002, ocorreram 2.343.760 partos, com uma taxa de 25,06 mortes por cada 1.000 nascidos vivos, e uma razão de mortalidade materna de 73,05 mortes por cada 100.000 nascidos vivos. (dados obtidos na página Departamento de Informação e Informática do SUS - DATASUS, www. datasus.gov.br). As necessidades de redução dos índices de mortalidade materna, de humanização dos partos e as perspectivas de saúde dos nascituros dependem, entre outros fatores, também fundamentalmente, da qualidade e da celeridade do atendimento nos serviços de saúde. (para mais detalhes a respeito, ver Silva, 1992; Theme-Filha et al.; 1999 Bale et al., 2003; Almeida et al., 2005, e Menezes et al., 2006). O tempo de espera pelo atendimento exerce papel inequívoco sobre a saúde das gestantes, das mães e dos recém-nascidos.

O presente trabalho tem por objetivo avaliar os tempos de espera no Sistema Único de Saúde Brasileiro - SUS -, para as internações relacionadas com o capítulo XV (Gravidez, Parto e Puerpério) da $10^{\text {a }}$ Revisão da Classificação Estatística Internacional de Doenças e Problemas Relacionados à Saúde - CID-10, conforme os dados disponíveis no DATASUS e apresentados em sua página na internet (www.datasus.gov.br). A descrição do Capítulo XV da CID-10 está no Apêndice 1 deste trabalho.

Uma boa discussão sobre o problema das filas em saúde está em Cullis et al., 2000. Conforme exposto em Marinho (2006) as filas são um resultado dos descompassos entre a demanda e a oferta, quando o sistema de preços não é o mecanismo determinante da produção e do consumo dos bens e produtos em saúde.

Para analisar as filas relacionadas com o capítulo XV da CID-10 no SUS, o presente trabalho é composto, basicamente, de dois estudos complementares. No primeiro, são estimados os tempos de espera para atendimento no SUS em um modelo clássico de teoria das filas (queueing theory). O segundo estudo identifica os determinantes desses tempos de espera, com o auxílio de um modelo econométrico multinível. A adoção de um modelo multinível traz uma série de vantagens ao presente trabalho. O Sistema Único de Saúde - SUS - caracteriza-se pela gratuidade, integralidade, universalidade, descentralização administrativa e controle social das ações. Embora, na prática, uma série de restrições (distâncias, custos de transporte, etc.) se imponham, as pacientes têm o direito de receber atendimento em qualquer unidade de saúde do sistema antes, durante e após o parto, desde que os recursos existam. Assim, surgem, potencialmente, interações, planejadas ou não, entre diversos municípios de um mesmo Estado (e, talvez em menor grau, até de Estados limítrofes, ou não). Como os fenômenos ligados ao parto têm um certo caráter emergencial, é certo que, na hipótese de falta de recursos nos seus municípios de origem, as parturientes busquem (ou sejam deliberadamente direcionadas) para atendimento em municípios com maior capacidade resolutiva ou mesmo na rede privada. (ver, para mais detalhes, Silva, 1992). Assim, é interessante considerar que municípios pertencentes a Estados com maiores disponibilidades de recursos e de serviços podem ter, talvez apenas por um efeito de nível mais elevado ("higher level effect”), tempos de espera para atendimento menores do que aqueles municípios que pertençam a Estados menos dotados. Um modelo econométrico multinível pode explicitar as possibilidades de interação entre o nível estadual e o municipal nos atendimentos aos procedimentos relacionados com a gravidez, o parto e o puerpério. 
Os modelos econométricos mais comuns, notadamente o método de mínimos quadrados ordinários (MQO), não são adequados quando os dados apresentam uma estrutura hierárquica como a que foi descrita nas linhas antecedentes. Podem existir correlações entre os municípios, gerando vieses nas estimativas das variâncias dos parâmetros estimados por MQO, que estariam subestimados, como foi demonstrado por Goldstein (1995). Os modelos multiníveis vêm sendo aplicados com freqüência crescente em estudos sobre saúde, conforme Rodríguez e Goldman (1995) - utilização de serviços de saúde por mulheres e crianças na Guatemala -, Jones (2000) - apresentação de modelos econométricos utilizados em Economia da Saúde - e Or, Wang e Jamison (2005) - estudo da variação da eficiência dos médicos na redução de mortalidade na OCDE.

Nosso modelo econométrico utiliza, como variáveis explicativas, fatores de risco materno, fatores assistenciais identificados no SUS e fatores de risco social. Algumas dessas variáveis estão relacionadas com a disponibilidade dos recursos humanos do SUS, disponíveis apenas na Pesquisa de Assistência Médica e Sanitária - MAS -, realizada pelo IBGE para os anos de 1999 e 2002. Essa limitação restringiu a amostra e o estudo aos dois referidos anos.

O texto está organizado da seguinte forma: a Seção 2 apresenta e aplica uma metodologia utilizada para avaliar as filas relacionadas com as internações no capítulo XV da CID-10 no Sistema Único de Saúde - SUS. A Seção 3 investiga a sensibilidade das dessas filas do SUS às variáveis da demanda e da oferta do sistema. A Seção 4 realiza, a partir dos resultados da seção precedente, um estudo econométrico do tipo multinível para avaliar os determinantes das filas em nível dos Estados, em nível dos municípios, e nos dois anos considerados (1999 e 2002). A Seção 5 apresenta as nossas Considerações Finais.

\section{A ESTIMATIVA DOS TEMPOS DE ESPERA PARA OS PROCEDIMENTOS RELACIONADOS COM A GESTAÇÃO NO SUS}

\subsection{Apresentação}

Não existem registros sistemáticos dos tempos de espera para internações relacionadas com a gestação (gravidez, parto e puerpério) no Sistema Único de Saúde - SUS. Para estimar estes tempos, recorreremos aos modelos de teorias das filas (queueing theory) que vêm tendo larga aplicação em saúde. (para mais detalhes, ver Marinho, 2006, que calcula os tempos de espera nas filas para transplantes no Brasil). A literatura (por exemplo, Panico, 1969, p. 101, e Green, 2004, p. 22) indica que tais modelos são particularmente úteis na análise de fenômenos relacionados com o parto. Embora natural, o fenômeno do parto configura-se em uma espécie de emergência, na medida em que o momento de ocorrência não pode ser perfeitamente previsto e cujo processo, uma vez deflagrado, não pode ser muito postergado. A demora no atendimento, usualmente, implica sérios riscos de saúde para a parturiente e para os nascituros. Por outro lado, os partos também não podem ser livremente agendados. $\mathrm{O}$ instante do parto tem um caráter fortemente aleatório, o que confere ao fenômeno um grau de exogeneidade adequado aos modelos de teoria das filas que serão utilizados no presente trabalho. (a este respeito ver Iversen, 1993).

A Tabela 1, a seguir, expõe algumas variáveis de interesse, relacionadas com as questões de saúde pertinentes ao capítulo XV da CID-10 e observadas no Sistema Único de Saúde - SUS. 
Tabela 1 - SUS (capítulo XV da CID-10): variáveis de interesse

\begin{tabular}{|c|c|c|c|c|c|}
\hline \multicolumn{6}{|c|}{ Variáveis } \\
\hline Ano & Internações* & $\begin{array}{l}\text { Crianças com baixo peso ao nascer } \\
\text { (menos do que } 2.500 \mathrm{~g} \text { ) }\end{array}$ & Cesarianas & $\begin{array}{l}\text { Despesa total com } \\
\text { saúde por habitante }\end{array}$ & Enfermeiros \\
\hline 1999 & 3.066 .466 & 246.207 & 660.266 & $91,32^{* *}$ & 70.175 \\
\hline 2002 & 2.731 .766 & 246.763 & 590.101 & 127,74 & 88.952 \\
\hline \multicolumn{6}{|c|}{ Variáveis } \\
\hline \multirow[t]{2}{*}{ Ano } & \multirow[t]{2}{*}{ Leitos obstétricos } & \multirow[t]{2}{*}{ Tempo médio de internação } & \multirow{2}{*}{$\begin{array}{l}\text { Médicos gineco- } \\
\text { obstetras }\end{array}$} & \multicolumn{2}{|c|}{ Freqüência de consultas de pré-natal } \\
\hline & & & & $\begin{array}{l}\text { Nenhum } \\
\text { consulta }\end{array}$ & $\begin{array}{c}\text { Sete ou mais } \\
\text { consultas }\end{array}$ \\
\hline 1999 & 71.929 & 2,3 & 56.053 & 173.180 & 1.510 .040 \\
\hline 2002 & 64.516 & 2,3 & 56.080 & 112.324 & 1.463 .469 \\
\hline
\end{tabular}

Fonte: Departamento de Informação e Informática do SUS - DATASUS. www.datasus.gov.br .

Notas: * capítulo XV da CID-10 (gravidez, parto e puerpério). ** As despesas com saúde por habitantes em 1999 são referentes ao ano base de 2000.

\subsection{Descrição dos modelos}

Um arcabouço bastante conhecido no estudo da teoria das filas de espera (queueing theory) em saúde baseia-se no uso dos intervalos de tempo decorrido entre as chegadas dos pacientes e da duração dos tratamentos recebidos por eles. O leitor interessado pode encontrar exemplos em Cox e Smith (1961) e em Hillier e Lieberman (1995). Um modelo clássico utiliza uma distribuição exponencial dos intervalos de tempo entre as chegadas das pessoas nas filas e uma medida do número de vezes que um evento ocorre em um processo de Poisson. Os intervalos de tempo relacionados com os serviços são assumidos como seguindo uma distribuição do tipo Erlang. Quando existe apenas um servidor (estação de atendimento: por exemplo, hospitais) e a distribuição Erlang tem parâmetro $k$, este modelo é conhecido como modelo “Markovian/Erlang/single server model $\left(M / E_{k} / 1\right)$ ". Embora relativamente simples, mesmo este modelo, em princípio, é muito difícil de aplicar em sistemas de saúde complexos. São necessários dados sobre os intervalos de tempo decorridos entre as chegadas dos pacientes entre os inícios e os términos dos tratamentos nas várias especialidades, clínicas e hospitais. A despeito destas dificuldades, existem, na literatura, fortes recomendações para a adoção desta metodologia. O leitor interessado pode consultar, por exemplo, Iversen (1986 e 1997), que estuda os efeitos da atuação de serviços privados em um sistema nacional de saúde, ou Iversen (1993), que elabora uma teoria para explicar as filas em hospitais, considerando uma proposta de alocação ótima de recursos e, ainda, Furukubo, Ohuchi e Kurokawa (2000), que propõem um método para analisar a espera em emergências hospitalares; também Mango e Shapiro (2001), que avaliam a adoção de procedimentos operacionais industriais, incluindo o uso de teoria das filas e de elementos de logística em hospitais nos Estados Unidos; além de Green (2004), que estuda aplicação de modelos de filas para a implementação de estratégias e práticas operacionais em hospitais.

Suponha-se que o tempo decorrido entre duas ocorrências consecutivas de um determinado evento (por exemplo, chegadas de parturientes em um hospital) seja representado por uma variável 
aleatória $T$. Diz-se que esta variável tem uma distribuição exponenciall com parâmetro $\lambda$ se a sua distribuição de probabilidade é:

$$
\begin{aligned}
& \mathrm{f}_{T}(t)=\lambda[\exp (-\lambda t)] \text { para } t \geq 0 \mathrm{e} ; \\
& \mathrm{f}_{T}(t)=0 \text { para } t<0 .
\end{aligned}
$$

Suponha-se que as parturientes chegando na fila em um hospital formem uma população que é uma fonte infinita de ocorrências desse fenômeno; sendo $\mathrm{X}(t)=\mathrm{n}$ uma variável aleatória representando o número de ocorrências. No exemplo, as ocorrências seriam a chegada das parturientes em um hospital no instante $t(t \geq 0)$, onde o instante 0 representa o instante no qual a contagem começa. Esta variável aleatória tem uma distribuição de Poisson com parâmetro $\lambda t$ e a seguinte função de distribuição de probabilidades:

$$
\mathrm{P}\{X(t)=n\}=(\lambda t)^{n}[\exp (-\lambda t)] / n ! \text { para } n=0,1,2,3 \ldots \ldots
$$

Se $\lambda t$ é muito grande a distribuição de Poisson se aproxima de uma distribuição normal com média e variância iguais a $\lambda t$.

A distribuição Erlang tem uma função densidade de probabilidades dada por:

$\mathrm{f}(\mathrm{t})=\left\{\left[(\mu \mathrm{k})^{\mathrm{k}}\right] \mathrm{t}^{\mathrm{k}-1} \exp (-\mathrm{k} \mu \mathrm{t})\right\} /\{\mathrm{k}-1\}$ !, para $\mathrm{t} \geq 0$. Os parâmetros $\mu$ e k são estritamente positivos e $\mathrm{k}$ é um número inteiro. A média dessa distribuição é igual a $1 / \mu$ e o desvio padrão é igual a $1 / \mu\left(\mathrm{k}^{0,5}\right)$. Fazendo-se $\mathrm{k}=1$ obtemos uma distribuição exponencial e fazendo $\mathrm{k}=$ infinito obtemos uma distribuição degenerada (constante). A distribuição Erlang é uma distribuição flexível e distingue-se da bastante conhecida distribuição gama apenas pelas restrições impostas aos parâmetros. A flexibilidade da distribuição Erlang será útil ao nosso estudo. Duas hipóteses básicas serão utilizadas. Primeiramente, supomos que os tempos de serviço (o prazo médio de internação) diferem muito entre as pacientes, de acordo com uma distribuição exponencial, ou seja, fazemos $\mathrm{k}=1$ no modelo $M / E_{k} / 1$. Nesse caso, temos o modelo conhecido na literatura como "Markovian/Markovian/single server model (M/M/1 model)". Este modelo é o mais simples e o mais utilizado na literatura. Este nome deriva do fato de que o modelo assume uma distribuição Markoviana dos intervalos de chegada, que são distribuídos de acordo com uma distribuição exponencial independente e identicamente distribuída (i.i.d.). Deste modo, o processo de chegada é um processo de Poisson. A distribuição dos tempos de internação segue um outro processo Markoviano e uma outra distribuição exponencial também i.i.d. Neste caso, existe apenas um ponto de atendimento (servidor). Esta será a opção metodológica em nosso estudo, porque os indicadores são todos normalizados pelo número de leitos, tratando o SUS como um único servidor, o que será detalhado e justificado mais adiante. No segundo caso, a única modificação em relação ao caso anterior é que supomos que os tempos de serviço para cada paciente são idênticos. Assim, nesse caso, fazemos $\mathrm{k}=$ infinito no modelo $M / E_{k} / 1$, de modo que o desvio padrão é igual a zero, a distribuição de probabilidades é degenerada (o tempo de serviço assume um valor constante) e obtemos o modelo "Markovian/Degenerate/single server model $(M / D / 1$ model)". Portanto, um amplo espectro de possibilidades de comportamento do tempo de internação é coberto no estudo. Pode ser demonstrado (ver Hillier e Lieberman, 1995) que o tempo estimado de espera na fila no modelo $M / M / s$ é o dobro do estimado no modelo $M / D / s$. Este fato

1 A apresentação do modelo está baseada em uma distribuição exponencial, que é um caso especial da distribuição Erlang. Isso ocorre porque a exponencial é simples, e muito mais conhecida do que a Erlang, que não é tão intuitiva. Usamos, ainda, uma distribuição degenerada, que é também um caso especial da Erlang, com a metade do tempo de espera estimado na exponencial. 
decorre de uma propriedade comum em modelos de filas, pois maiores variabilidades e maiores imprevisibilidades impõem piores desempenhos aos modelos.

\subsection{A adaptação do modelo ao SUS}

É possível adaptar os modelos $M / M / 1$ e $M / D / 1$ para aplicação em sistemas de saúde complexos. O leitor interessado nas adaptações desse modelo ao SUS pode consultar Marinho (op. cit). Na clínica obstétrica, um exemplo de aplicação direta do modelo $M / M / s$ está em Green (2004). Ackere e Smith (1999), adaptam o modelo $M / M / 1$ para o National Health System do Reino Unido. O procedimento consiste em avaliar o sistema como uma única estação de trabalho (servidor) com uma única fila. Ressalte-se que, tecnicamente, seria impossível caracterizar um modelo de filas com milhares de servidores (pontos de atendimento). Procedimento similar será adotado no presente trabalho para avaliar as internações referentes ao capítulo XV da CID-10 (gravidez, parto e puerpério) no Sistema Único de Saúde - SUS.

Os passos para estimar as variáveis-chave do modelo são os seguintes:

1. Sejam as seguintes variáveis e relações disponíveis no SUS, em valores de final de ano, conforme disponível no Sistema de Informações Hospitalares - SIH do Departamento de Informática do SUS-DATASUS em sua página na Internet:

A: número de casos tratados em um ano, que consta na Tabela 1 anterior. Fonte: SIH/Datasus;

B: número de leitos obstétricos disponíveis, que consta na Tabela 1 anterior. Fonte: SIH/ DATASUS. Vale a ressalva de que outros tipos de leitos podem ser utilizados para o atendimento, mas não temos como verificar em que magnitude isso ocorreria. Mas cabe aqui um comentário: Menezes et al. (2006, p. 554), tratando dos problemas de acesso aos serviços de saúde pelas gestantes no município do Rio de Janeiro, que é um dos municípios com maior cobertura, afirmam que "em estudo realizado em 1998 pelo Conselho Regional de Medicina do Rio de Janeiro (CREMERJ) foi estabelecida a necessidade de três leitos de UI e um leito de UTI neonatal para cada mil nascidos vivos. Nenhum Estado brasileiro está próximo desta meta." E, mais ainda, (ibid): "a falta de leitos intensivos, e semi-intensivos para o recém-nascido, torna-se, portanto, o principal fator limitante para internações de gestantes com possibilidades de parto prematuro". Prosseguindo, Menezes et al. (p. 556) afirmam que "além da falta de leitos de UI e de UTI neonatal, deve-se considerar a desigualdade da oferta de leitos no município".

T: o tempo médio gasto para tratar cada caso, ou seja, o tempo médio de internação, em dias, por caso, também conforme a Tabela 1. Fonte: SIH/Datasus.

2. A partir dessas variáveis, outras duas de interesse do presente estudo são obtidas, e apresentadas na Tabela 2, a seguir:

$\mathrm{R}=(\mathrm{A} / \mathrm{B}) / 365$ : razão de casos por leito por dia, ou seja o número de casos tratados no SUS por leito e por unidade de tempo. R, a taxa de chegada de pacientes, é a variável representativa da demanda por serviços de internação no SUS. R depende, basicamente, das taxa de fecundidade e de natalidade das usuárias do SUS.

$\mathrm{S}=1 / \mathrm{T}$ : a taxa média de serviço ou de atendimento, ou seja, o número de casos tratados, em cada leito, por unidade de tempo. S é a variável representativa da oferta de serviços de internação no sistema. Essa variável depende, basicamente, dos recursos utilizados, do esforço e da tecnologia médica empregados em cada caso. Trata-se de um indicador complexo, sem que haja um consenso teórico a respeito das interpretações e do uso que se possa fazer dele e que merece alguma discussão. Uma primeira interpretação é que o prazo médio de internação é 
um indicador de qualidade. Quanto menor o prazo, ceteris paribus, melhor para o paciente, e melhor a qualidade do atendimento. Mas sempre se pode argüir que altas precoces impliquem pacientes em pior situação de saúde ("quicker but sicker"). Essa hipótese implica a endogeneidade do indicador. Os hospitais, em algum grau, controlariam os prazos de internação. Mas determinar se esse controle ocorreria à custa da saúde dos pacientes é uma questão empírica, fora do alcance do presente texto. Existe também a possibilidade de que menores prazos decorram dos avanços da Medicina ou de cuidados diários mais intensivos. Outra interpretação é que os prazos são exógenos, diretamente relacionados com a complexidade ou gravidade dos casos. Maiores prazos estariam relacionados com fatores fora do controle do hospital, e não indicam má qualidade de atendimento. Alternativamente, o prazo médio de internação também seria uma medida de produção e modos alternativos de remuneração dos hospitais exercem influências diversas sobre esses prazos. Orçamentos fixos, por procedimentos e pagamentos per capita, tenderiam a incentivar menores prazos médios de internação nos hospitais. Pagamentos per diem tenderiam a tornar maiores os prazos de permanência.

3. Com estas variáveis, pode-se, no modelo $M / M / s$, calcular outros elementos de interesse. Embora sejam clássicas, as fórmulas que se seguem são de obtenção trabalhosa e extensa, sendo, por isso, omitidas. Os cálculos são baseados em elementos de Cadeias de Markov e estão rigorosamente desenvolvidos, por exemplo, em Hillier e Lieberman (1995):

$\mathrm{U}=\mathrm{R} / \mathrm{S}=\mathrm{RxT}$, o fator de utilização, fração esperada do tempo em que um leito estará ocupado e que é igual à probabilidade de que um caso aleatório encontre um leito ocupado;

1-U: a probabilidade que um paciente aleatório que chegue ao SUS encontre um leito vazio. Este resultado, conforme demonstram Gross e Harris (1998, p. 274-279), pode ser generalizado para uma larga classe de modelos ("General input/General service/single server model-G/ $\mathbf{G} / \mathbf{1}$ ”), para quaisquer que sejam as (para arbitrárias) distribuições dos intervalos de tempo de chegada e de serviço;

$\left(\mathrm{W}_{\mathrm{q}}\right)=\mathrm{W}-\mathrm{T}=\mathrm{U} /(\mathrm{S}-\mathrm{R})$ : tempo médio esperado na fila (exclui o tempo médio de internação); $\mathrm{W}=\mathrm{W}_{\mathrm{q}}+\mathrm{T}$ : tempo total de espera no SUS (inclui o tempo médio de internação);

$\mathrm{P}\left(\mathrm{W}_{\mathrm{q}}>t\right)=\mathrm{U}\{\exp [-\mathrm{S}(1-\mathrm{U}) t]\}:$ probabilidade que um paciente aleatório espere mais do que $t$ dias na fila.

Os resultados para essas variáveis são, usualmente, apresentados sem intervalos de confiança associados. Lilliefors (1966) obteve um intervalo para o tempo de espera total (W), mas que não costuma ser explorado na literatura subseqüente. Como o interesse principal de nosso trabalho reside no tempo de espera na fila $\left(\mathrm{W}_{\mathrm{q}}\right)$, nos abstivemos de utilizar tal resultado.

Os resultados da aplicação do modelo ao SUS encontram-se na Tabela 2 a seguir. 
Tabela 2 - Resultados da aplicação dos modelos $M / M / 1$ e $M / D / 1$ no capítulo XV da CID-10: taxa de serviço (S), taxa de chegada de pacientes (R), prazo médio de internação (T), tempo de espera total $(\mathrm{W})$, tempo de espera na fila $\left(\mathrm{W}_{\mathrm{q}}\right)$, probabilidade de encontrar leito vazio (1-U) e probabilidade de esperar mais do que um dia para ser atendida $\left(\mathrm{P}\left(\mathrm{W}_{\mathrm{q}}>1\right)\right.$

\begin{tabular}{lcc}
\hline Variáveis & Resultado (ano de 1999) & Resultado (ano de 2002) \\
\hline$R$ (pacientes/leito.dia) & 0,1168 & 0,1160 \\
$\mathrm{~S}$ (pacientes/leito.dia) & 0,4348 & 0,4348 \\
$\mathrm{~T}$ (dias) & 2,3 & 2,3 \\
$W(M / M / 1)$ (dias) & 3,1447 & 3,1369 \\
$W_{q}(M / M / 1)$ (horas) & 20,2728 & 20,0856 \\
$1-U$ & $73,14 \%$ & $73,32 \%$ \\
$P\left(W_{q}>1\right)$ & $19,54 \%$ & $19,40 \%$ \\
$W(M / D / 1)$ (dias) & 2,7224 & 2,7185 \\
$W_{q}(M / D / 1)$ (horas) & 10,1364 & 10,0428 \\
\hline
\end{tabular}

Os resultados apresentados na Tabela 2 anterior são, em princípio, preocupantes, atestando a demora e a incerteza no atendimento do atendimento relacionado ao parto no Brasil já apontado na literatura. (por exemplo, Silva, 1992; Theme-Filha et al., 1999; Almeida et al., 2005, e Menezes et al., 2006). Em média, no SUS, nos dois anos estudados, a espera para o atendimento $\left(\mathrm{W}_{\mathrm{q}}\right)$ para problemas relacionados com a gravidez, parto e puerpério, teria demorado, aproximadamente, 20 horas em um modelo mais pessimista (o modelo $M / M / 1$ ) e em torno 10 horas em um modelo mais otimista (o modelo $M / D / 1$ ). Por oferecer um limite superior do desempenho do sistema, o modelo otimista merecerá a maior parte de nossos comentários. Vale reafirmar, entretanto, que os resultados são válidos para todos os procedimentos do capítulo XV da CID-10 e não apenas para os partos. Note-se, ainda, que esse prazo é melhor do que o encontrado para as internações no SUS como um todo para o ano de 2003, por Marinho (2004), que reporta um tempo de espera de, aproximadamente, 4,5 dias em média. O período de tempo total gasto no sistema (W) varia entre aproximadamente 3,1 dias no modelo $M / M / 1$ e 2,7 dias no modelo $M / D / 1$, o que implica uma média em torno de 2,9 dias. Ressalte-se, entretanto, que existem grandes variações dos resultados entre os municípios e entre os Estados da Federação, conforme será comentado a seguir. As probabilidades (1-U) de uma paciente encontrar leitos vazios estão em torno de 73\%, o que coloca a probabilidade de encontrar leitos ocupados em torno de $27 \%$. Este, conforme vimos, é um resultado que independe da distribuição dos tempos de chegada e de serviço (é válido no modelo $G / G / 1$ ). Não são esses, novamente, indicadores de pronto atendimento para gestantes, parturientes e puérperas no SUS. Vê-se, no modelo $M / M / 1$, que as probabilidades $\mathrm{P}\left(\mathrm{W}_{\mathrm{q}}>1\right)$ de que uma paciente espere mais do que um dia para ser atendida estão em torno de 19,5\%. Este resultado não configura uma situação confortável, com todos os riscos inerentes a uma probabilidade nada desprezível de que ocorra uma espera de tal magnitude.

Existe uma dispersão de resultados entre os Estados da Federação, cujos resultados estão no Apêndice 2. Em linhas gerais, nota-se uma estabilidade dos tempos das filas nos Estados, entre os anos de 1999 e 2002. Em 2002, observa-se, no modelo M/D/1, o mais otimista, que onze Estados apresentam tempos de espera maiores do que 12 horas e que isso ocorria em 10 Estados em 1999. Os resultados do Distrito Federal são problemáticos (tempo de espera maior do que 48 horas) em 
ambos os anos, parecendo ocorrer alguma superposição de informações com o Estado de Goiás. O Amapá apresenta tempo de espera maior do que 24 horas em 2002. Os Estados do Acre (com dados e resultados de magnitudes inconsistentes), Amapá e Rio de Janeiro apresentam resultados muito ruins (tempos de espera maiores do que 24 horas) no ano de 1999. O Estado de Roraima, e a sua capital, Boa Vista, não apresentam dados disponíveis para ano de 1999.

Nas capitais dos Estados, observamos, no ano de 2002, 22 capitais com tempos de espera maiores do que 12 horas. Isto ocorria com 21 capitais no ano de 1999. Doze capitais apresentavam tempos de espera maiores do que 24 horas em 2002, o que ocorria em 15 capitais no ano de 1999. Recife, Salvador e Florianópolis apresentam resultados problemáticos (tempo de espera maior do que 48 horas) no ano de 2002. Tempos de espera maiores do que 48 horas foram encontrados para Porto Velho, Rio Branco, Macapá e Salvador em 1999. Não existem os dados necessários ao modelo para Boa Vista no ano de 1999. Por restrições de espaço não apresentamos os resultados por capitais e demais municípios, mas esses estão disponíveis com os autores.

O mesmo modelo otimista $(M / D / 1)$ encontra resultados de tempos de espera menores do que 12 horas em ambos os anos nos Estados da Bahia, Ceará, Goiás, Maranhão, Mato Grosso, Mato Grosso do Sul, Minas Gerais, Paraná, Paraíba, Pará, Rio Grande do Norte, Rio Grande do Sul, Rondônia e Tocantins. O modelo $M / D / 1$ aponta resultados menores do que 12 horas, em ambos os anos, nas cidades de Teresina e Campo Grande.

Como se pode ver, mesmo o modelo otimista aponta uma estabilidade do desempenho (em média, bastante ruim) do SUS nos dois anos. O estudo também aponta que a situação é bem pior nas capitais do que nos demais municípios em geral.

\section{AS ELASTICIDADES DOS TEMPOS DE ESPERA PARA INTERNAÇÕES NO SUS RELA- CIONADAS COM O CAPÍTULO XV DA CID-10 (GRAVIDEZ, PARTO E PUERPÉRIO)}

Em Marinho (2004), são apresentadas as elasticidades (sensibilidades) dos diferentes tipos de tempos de espera do modelo em relação às variações na taxa de serviço (S), na taxa de chegada de pacientes $(\mathrm{R})$, em relação à variações na diferença entre estas duas taxas $(\mathrm{S}-\mathrm{R})$, e em relação a variações no número de leitos (B). No presente estudo, serão calculadas apenas as elasticidades do tempo de espera na fila $\left(\mathrm{W}_{\mathrm{q}}\right)$, conforme a Tabela 3 a seguir.

Tabela 3 - Resultados da aplicação dos modelos $M / M / 1$ e $M / D / 1$ no capítulo XV da CID-10. Elasticidades do tempo na fila $\left(\mathrm{W}_{\mathrm{q}}\right)$ em relação às variáveis selecionadas: taxa de serviço $(\mathrm{S})$, taxa de chegada de pacientes $(\mathrm{R})$, diferença entre taxas $(\mathrm{S}-\mathrm{R})$, e número de leitos (B)

\begin{tabular}{lccc}
\hline Variáveis & Fórmula da elasticidade ${ }^{*}$ ) & Valor (ano de 1999) & Valor (ano de 2002) \\
\hline $\mathrm{S}$ & $\eta_{\mathrm{q}}=-(2 \mathrm{~S}-\mathrm{R}) /(\mathrm{S}-\mathrm{R})<-1$ & $-2,3673$ & $-2,3639$ \\
$\mathrm{R}$ & $\varepsilon_{\mathrm{q}}=\mathrm{S} /(\mathrm{S}-\mathrm{R})>1$ & 1,3673 & 1,3639 \\
$\mathrm{~S}-\mathrm{R}$ & $\gamma_{\mathrm{q}}=-1$ & -1 & -1 \\
$\mathrm{~B}$ & $\varphi_{\mathrm{q}}=-\varepsilon_{\mathrm{q}}=-\mathrm{S}(\mathrm{S}-\mathrm{R})<-1$ & $-1,3673$ & $-1,3639$ \\
\hline
\end{tabular}

$\left(^{*}\right)$ para os detalhes de obtenção das fórmulas, ver Marinho (2004). 
Observa-se que as relações entre os tempos de espera nas filas $\left(\mathrm{W}_{\mathrm{q}}\right)$ e as variáveis operacionais do sistema (S; R; S-R; e B) não são lineares, e as diversas elasticidades podem ou não ser constantes. Os tempos de espera são mais elásticos (sensíveis) à oferta (a taxa de atendimento S) do que à demanda (a taxa de chegada R). A elasticidade dos tempos de espera em relação à capacidade fixa instalada, ou seja, dos leitos (B), tem o valor de -1,36. A elasticidade de oferta $\left(\eta_{\mathrm{q}}\right)$, nos dois anos, tem valor em torno de $-2,36$, ao passo que a elasticidade de demanda $\left(\varepsilon_{\mathrm{q}}\right)$, nos dois anos, está em torno de 1,36. Assim, as políticas que podem expandir a oferta apresentam, potencialmente, um elevado efeito de redução dos tempos de espera. Uma expansão de $1 \%$ na taxa de atendimento implica uma redução de 2,36\% nos tempos de espera. Uma expansão de $1 \%$ no número de leitos implica uma redução de $1,36 \%$ nos tempos de espera. Reduções iguais na taxas de serviço teriam efeitos simétricos. O mesmo vale para reduções no número de leitos. Já um aumento da demanda de $1 \%$ significaria um aumento dos tempos de espera em torno de $1,36 \%$.

\section{OS DETERMINANTES DOS TEMPOS DE ESPERA PARA INTERNAÇÕES NO SUS RELA- CIONADAS COM O CAPÍTULO XV DA CID-10 (GRAVIDEZ, PARTO E PUERPÉRIO)}

\subsection{Apresentação dos modelos econométricos multiníveis}

Esta seção apresenta um conjunto de regressões destinadas a estabelecer as relações entre variáveis representativas de fatores de risco materno, fatores assistenciais presentes no SUS, fatores de risco social e, como variável de desfecho, os prazos de espera para internações referentes ao capítulo XV da CID-10, observados no Sistema Único de Saúde, nos Estados e nos municípios brasileiros. Para os municípios, serão utilizados modelos do tipo multinível, conforme será exposto a seguir. Para os Estados, serão utilizados modelos em painel, considerando os dois anos da amostra e apenas variáveis observadas em nível dos Estados.

Em busca de atendimento para os fenômenos sanitários relacionados com a gravidez, o parto e o puerpério, os usuários do SUS podem ir além de seus municípios de origem, em virtude do grau de urgência envolvido e da busca pela qualidade. (para uma análise da peregrinação das parturientes pelo SUS no município do Rio de Janeiro, ver Menezes et al., 2006). Não é raro que as parturientes, e os demais casos mais complexos, sejam efetivamente atendidos fora de seus municípios de origem, apesar das diretrizes constitucionais de hierarquização e de regionalização do SUS. Em maiores, ou em menores graus, existem esforços de regionalização, de consorciamento e de cooperação entre municípios, em alguns casos sob a coordenação das Secretarias Estaduais de Saúde. Tais esforços visam evitar a duplicação de esforços entre municípios próximos, cujas dimensões populacionais ou as disponibilidades de recursos inviabilizem a oferta de toda a gama de recursos e de serviços necessários ao atendimento, principalmente aqueles de maior complexidade. Esse é, inclusive, um dos objetivos do Plano Diretor de Regionalização - PDR. Caso haja necessidade, por exemplo, em urgências, os pacientes de um determinado município podem se beneficiar dos recursos disponíveis em outros municípios, ou seja, dos recursos disponíveis em nível estadual. Os tempos de espera para atendimento serão determinados em nível municipal, mas, certamente, também sofrerão a influência da estrutura do SUS nos Estados. Acreditamos, portanto, que os modelos multiníveis podem ser úteis para explicitar, caso ocorram, interações entre os desfechos em nível municipal e as características dos Estados dos quais os municípios fazem parte. 
Os modelos de regressão multinível consistem em uma estrutura de regressão múltipla, nos quais os dados são hierarquizados, ou seja, estão contidos em diversas microunidades contidas em diversas macrounidades. Procura-se, nesses modelos, explorar as variações observadas nos diversos níveis da hierarquia, após o condicionamento do conjunto de variáveis explicativas de interesse. Assim, a variável dependente, eventualmente, sofre influências das variáveis independentes em diversos níveis de agregação. A estrutura geral dos modelos multiníveis guarda, conforme veremos, semelhanças com os modelos em painel, mas as variáveis podem estar indexadas por outras variáveis que não o tempo de observação. (para mais detalhes, ver o capítulo 14 de Greene, 1997). Para mais informações sobre a aplicação desses modelos em sistemas de saúde, ver Rodriguez e Goldman (1995); Jones (2000), e Or, Wang e Jamison (2005).

Seja, a título de exemplo, $\mathrm{W}_{\mathrm{jk}}$ o resultado relacionado com as variáveis explicativas $X$ do seguinte modo:

$$
\mathrm{W}_{\mathrm{jk}}=\mathrm{X}_{\mathrm{jk}} \beta+\mu_{\mathrm{j}}+\varepsilon_{\mathrm{jk}}
$$

$\varepsilon_{\mathrm{jk}}$ é o erro aleatório no município $k$ no Estado $j$ e $\varepsilon_{\mathrm{jk}}$ tem média zero e variância $\sigma_{\varepsilon^{2}}^{2}$. Os efeitos dos Estados são estimados por meio de $\mu_{\mathrm{j}}$ que é aleatório e tem média zero e variância $\sigma_{\mu}^{2}$. Por exemplo, $\mathrm{W}_{\mathrm{jk}}$ poderia representar o tempo de espera para atendimento no município $k$ no Estado $j$ da Federação. Assume-se que os efeitos nos municípios (primeiro nível) e nos Estados (segundo nível) são não correlacionados e a co-variância $\operatorname{cov}\left(\varepsilon_{\mathrm{j} k}, \mu_{\mathrm{j}}\right)=0$. Para o $k$-ésimo município no $j$-ésimo Estado a variância condicional é $\operatorname{var}\left(\mathrm{W}_{\mathrm{jk}} / \mathrm{X}_{\mathrm{jk}} \beta\right)=\sigma_{\mu}+\sigma_{\varepsilon}^{2}$ e a variância total é dividida em dois componentes, um para os Estados e outro para os municípios. A divisão da variância leva ao coeficiente de correlação intragrupo, $\rho=\sigma_{\mu}^{2} /\left(\sigma_{\mu}^{2}+\sigma_{\varepsilon}^{2}\right)$, que mede o poder explicativo do agrupamento dentro da hierarquia dos dados e é fundamental para a estimação dos modelos multiníveis. Como as variâncias nos diferentes níveis são diferentes, os modelos tradicionais de regressão sofrem percalços mais facilmente contornáveis em modelos multiníveis ou de painel (ver Greene, 1997).

\subsection{Os modelos estimados}

Os modelos foram estimados em três níveis: municípios (nível 1), Estados (nível 2) e os anos de 1999 e 2002 (nível 3). Ressalte-se que os dados referentes ao ano de 1999 apresentam algumas inconsistências, com ausência de dados e valores de variáveis completamente irrealistas, principalmente para os pequenos municípios das regiões norte e nordeste do País e que foram retiradas da amostra. Não foram avaliados efeitos em outros níveis de agregação, devido à inexistência de consenso sobre o real significado que poderíamos efetivamente observar no que se refere à regionalização das ações de saúde no SUS.

Um outro ponto importante, já abordado na subseção 2.3, refere-se aos prazos excessivamente longos previstos para alguns municípios. Para mitigar tal problema, duas amostras distintas foram utilizadas. Na primeira, que chamaremos de amostra irrestrita, todos os municípios com dados disponíveis foram incluídos. Na segunda amostra, que chamaremos de amostra restrita, apenas os municípios com tempos de espera menor do que 3 (três) dias $\left(\mathrm{W}_{\mathrm{q}}<3\right)$ foram incluídos. O Departamento de Neonatologia da Sociedade Brasileira de Pediatria - SBP - aprovou Documento Científico (disponível em http://www.sbp.com.br/show_item2.cfm?id_categoria=21\&id_detalhe=1636\&tipo_ detalhe=s) que preconiza, entre outros diversos aspectos relacionados com a gravidez, o parto e o puerpério que "as instituições devem realizar o atendimento à mãe e ao recém-nascido com procedimentos humanizados...". No referido documento, consta, ainda que "o retorno ambulatorial de todos 
os recém-nascidos de baixo risco (grifo nosso)...deve ser realizado, no máximo, 48-72 horas após a alta hospitalar na presença da mãe". Assim, além das questões de razoabilidade já citadas, entendemos que se uma atividade (que a SBP enfatiza que deveria ser rotineira) para recém-nascidos de baixo risco, e para as respectivas mães, não deve ultrapassar o prazo de 72 horas, esse não seria um limite superior de segurança excessivo para os casos do capítulo XV da CID-10.

\section{Um modelo geral de 3 níveis}

Considere-se a situação onde a variável de resposta $\mathrm{w}^{\mathrm{q}}$, representando o tempo de espera nas filas, depende de $p$ variáveis explicativas $\mathrm{x}_{1}, \mathrm{x}_{2}, \ldots, \mathrm{x}_{\mathrm{p}}$. Um modelo geral de 3 níveis será definido como:

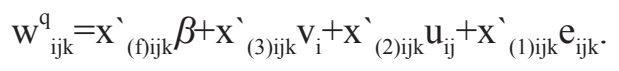

Onde:

$\mathrm{i}=1,2, \ldots, N$ representa o nível 3, no caso, os anos de observação.

$\mathrm{j}=1,2, \ldots, n_{i}$ representa o nível 2, no caso, os Estados.

$\mathrm{k}=1,2 \ldots, n_{i j}$ representa o nível 1 , no caso, os municípios.

$\mathrm{x}^{`}{ }_{(\mathrm{f}) \mathrm{jk}}$ : $1 x s$ é uma coluna da matriz da parte fixa do modelo, e os seus elementos são um subconjunto do conjunto das $p$ variáveis explicativas.

$\mathrm{x}^{`}{ }_{(3) \mathrm{ij}}$ : $1 x q$ é uma coluna da matriz da parte aleatória do modelo em nível 3, e os seus elementos são um subconjunto do conjunto das $p$ variáveis explicativas.

$\mathrm{x}^{`}{ }_{(2) \mathrm{ij} \mathrm{j}}: 1 \mathrm{xm}$ é uma coluna da matriz da parte aleatória do modelo em nível 2, e os seus elementos são um subconjunto do conjunto das $p$ variáveis explicativas.

$\mathrm{x}^{`}{ }_{(1) \mathrm{ijk}}: 1 x r$ é uma coluna da matriz da parte aleatória do modelo em nível 1, e os seus elementos são um subconjunto do conjunto das $p$ variáveis explicativas.

$\beta$ : $s x 1$ é um vetor de parâmetros fixos, mas desconhecidos, a serem estimados.

Assume-se que $\mathrm{v}_{1}, \mathrm{v}_{2}, \ldots \mathrm{v}_{N}$ são independentes e identicamente distribuídos (i.i.d), com média zero e matriz de covariância $\Phi_{(3)}$. Assume-se, também, que $\mathrm{u}_{\mathrm{i} 1}, \mathrm{u}_{\mathrm{i} 2}, \ldots, \mathrm{u}_{\mathrm{i} n i}$ são i.i.d. com média zero e matriz de covariância $\Phi(2)$, enquanto $\mathrm{e}_{\mathrm{ij} 1}, \mathrm{e}_{\mathrm{ij} 2}, \ldots, \mathrm{e}_{\mathrm{ij} n i j}$ são i.i.d. com média zero e matriz de covariância $\Phi_{(1)}$. Assume-se, adicionalmente, que $\mathrm{v}_{\mathrm{i}}, \mathrm{u}_{\mathrm{ij}}$ e $\mathrm{e}_{\mathrm{ijk}}$ são independentes e que são normalmente distribuídos.

Complementando o modelo linear, de acordo com recomendações de Siciliani e Hurst (2003), julgamos interessante identificar as variáveis associadas com as probabilidades de existência ou não de filas, independentemente da magnitude das mesmas. Com este objetivo, foram executados modelos do tipo probit nas duas amostras (ampla e restrita) utilizadas no estudo. Infelizmente, os resultados obtidos não muito foram satisfatórios, mas vale o registro dessa alternativa metodológica. Para aplicação e discussão de modelos com resposta binária em contexto de regressões multinível, ver Greene (1997) e Rodriguez e Goldman (2001).

\subsection{Descrição das variáveis utilizadas}

A variável dependente é o tempo de espera nas filas nos Estados e nos municípios, obtidos nos modelos $M / M / 1$ e $M / D / 1$.

As variáveis explicativas são uma tentativa simplificada de representar fatores que podem influenciar, de modo positivo ou negativo, os tempos de espera para atendimento no capítulo XV da CID-10 no SUS, nos Estados e nos municípios. Além do próprio ano de observação, que representa 
o nível três do modelo, estas variáveis estão divididas em três grupos básicos: fatores de risco materno, fatores assistenciais e fatores de risco social. Uma extensa discussão sobre os riscos de internação nesse contexto está em Schramm et al. (2002).

\section{Fatores de risco materno:}

1. Número de nascimentos com baixo peso (menor do que 2,500 kg) dividido pelo número de partos: o peso ao nascer é um indicativo clássico de risco e indicativo de complicações pós-parto. (ver Schramm et al., 2002, e Silva, 1992). Assim, o peso abaixo de $2.500 \mathrm{~kg}$ pode significar maior prazo de internação, com o conseqüente congestionamento do sistema e aumento do prazo de espera quanto maior for a ocorrência desse fenômeno. Vale ressaltar que, se uma criança ficar internada mais do que 72 horas, uma nova Autorização de Internação Hospitalar - AIH - será aberta, sendo considerada uma nova internação para a criança. A divisão pelo número de partos normaliza o indicador entre os municípios e Estados com freqüências absolutas diferentes no numerador do indicador. Espera-se um sinal positivo para a correlação dessa variável com o tempo de espera nas filas. Fonte: Sinasc/Datasus.

2. Número de cesarianas dividido pelo número de partos: as cesarianas são um procedimento indicador de risco para as gestantes e para as crianças, e que alonga os prazos de recuperação e de internação, embora também, freqüentemente, estejam associadas a fatores biológicos, socioeconômicos e culturais. (ver Schramm et al., 2002, e Silveira e Santos, 2004a). Por outro lado, as cesarianas dariam aos médicos uma certa capacidade de programar os partos e "organizar" o sistema, o que tenderia a diminuir as filas. A priori, o sinal da correlação desta variável com os prazos de espera para atendimento é imprevisível. Fonte: SIH/Datasus.

3. Número de partos sem consultas de pré-natal dividido pelo número de partos: indica uma reduzida preocupação com a qualidade do parto. O exame pré-natal é um pré-requisito básico para a segurança da gestação e do parto. Trata-se de um indicador clássico da qualidade de cuidados clínico e de saúde pública. (Silveira e Santos, 2004b). A recomendação do Ministério da Saúde é de realização de, no mínimo, 6 consultas de acompanhamento pré-natal. Essa recomendação está expressa na Portaria, No $569 / \mathrm{MS}$ de $1^{\circ}$ de junho de 2000. Entretanto, na página do Sinasc/Datasus na internet (http://tabnet.datasus.gov.br/cgi/deftohtm.exe? sinasc/cnv/nvbr. def), somente estão disponíveis as seguintes tabulações para o número de exames realizados: "nenhuma; 1 a 3; 4 a 6; 1 a 6 não especificado; 7 ou mais; ignorado". Assim, tivemos de optar por 7 ou mais exames. Espera-se que esta variável tenha uma correlação positiva com os prazos de espera para atendimento. Fonte: Sinasc/Datasus.

4. Número de partos com número realizado de exames pré-natal maior do que sete dividido pelo número de partos: indica uma expressiva preocupação com a qualidade da gestação e do parto. Embora reconheçamos que a qualidade dos exames (variável não disponível no SUS) é tão importante quanto a freqüência (para mais detalhes, ver Silveira et al., 2001; Coutinho et al., 2003, e Silveira e Santos, 2004b), essa variável denota, ao menos, uma predisposição inicial para o correto atendimento das gestantes. Espera-se que esta variável tenha uma correlação negativa com os prazos de espera para atendimento. Fonte: Sinasc/Datasus.

\section{Fatores assistenciais:}

5. Número de médicos gineco-obstetras dividido pelo número de internações: indica a disponibilidade de recursos médicos especializados no atendimento às gestantes. A divisão pelo número de internações normaliza o indicador entre os municípios e Estados com freqüências absolutas diferentes no numerador do indicador. Por um lado, o aumento do número relativo desses profissionais deveria reduzir os tempos de espera nas filas, por se tratar, em princípio, de aumento na capacidade de prestação de serviços. Entretanto, a literatura aponta uma variada 
gama de situações em que, por conflito de interesses, o oposto pode ocorrer, notadamente, na presença de um setor privado de atendimento, atuando paralelamente ao setor público (a este respeito ver, especialmente, Ackere e Smith, 1999, e Cullis et alli, 2000). Não existiria, portanto, uma expectativa muito segura em relação ao sinal da correlação dessa variável com os prazos de espera para atendimento. Fonte AMS/Datasus.

6. Número de enfermeiros (com nível superior) dividido pelo número de internações: do mesmo modo que a variável anterior, indica a disponibilidade de recursos humanos qualificados para o atendimento às gestantes. Espera-se que esta variável tenha uma correlação negativa com os prazos de espera para atendimento, mas deve-se considerar o fato de que o total geral de enfermeiros não é um recurso exclusivo para as gestantes e para os nascituros, sendo disputado por outros pacientes e instâncias do SUS. Fonte: AMS/Datasus.

7. Despesa total com saúde por habitante: indica o esforço financeiro realizado pelo setor público (Estados e municípios) no setor saúde. Em princípio, por denotar uma preocupação com a qualidade do atendimento, espera-se que esta variável tenha uma correlação negativa com os prazos de espera para atendimento. Assim como no item anterior, deve-se observar que a despesa total com saúde por habitante engloba toda a gama de serviços oferecidos para a população, ocorrendo perda de especificidade. Fonte: SIOPS/Datasus.

8. Coeficiente de importação de internações: o SUS informa, para cada município e para cada Estado, o número de internações por local de internação (I) e o número de internações por local de residência (R). A razão (I-R)/R é uma medida do esforço que um município ou Estado faz para atender residentes em outros municípios ou Estados. Em municípios ou Estados que tratem um número de casos maior do que o número de residentes, ou seja, nas unidades importadoras líquidas, essa variável assumirá um valor positivo. Um valor negativo ocorrerá em exportadores líquidos. Espera-se que esta variável tenha uma correlação positiva com os prazos de espera para atendimento. Fonte: SIH/Datasus.

\section{Fatores de risco social:}

9. Índice de Desenvolvimento Humano - IDH (ano 2000). O índice de Desenvolvimento Humano - IDH. Como é um indicador clássico de desenvolvimento e de risco social, combinando elementos de indicadores de educação (alfabetização, taxa de matrículas), saúde (esperança de vida ao nascer) e renda (renda per capita) espera-se que as regiões mais desenvolvidas do País, e com maiores valores de IDH, apresentem menos problemas de atendimento e menores tempos na s filas. Somente está disponível, em nível municipal, para o ano 2000. Assim, a mesma série para os Estados e para os municípios será utilizada para o ano de 1999 e para o ano de 2002. Fonte: Ipeadata.

10. taxa de fecundidade total: número médio de filhos que uma mulher teria ao terminar o período reprodutivo. Como a taxa de fecundidade afeta diretamente a demanda por atendimento, espera-se que esta variável tenha uma correlação positiva com os prazos de espera para atendimento. Como somente está disponível, em nível municipal, para o ano 2000, a mesma série, para os Estados e para os municípios, será utilizada no ano de 1999 e para o ano de 2002. Fonte: Ipeadata.

Períodos de observação: Os períodos de observação foram representados por uma variável do tipo dummy, que assume o valor zero para 1999 e 1 para 2002.

A quantidade de leitos obstétricos disponíveis, a quantidade de internações e o prazo médio de internação não foram incluídos nas regressões por fazerem parte do cálculo dos tempos de espera, que é a variável dependente da regressão (ver subseção 2.3). O software utilizado foi o STATA ${ }^{\mathrm{tm}}$ 
9.0, Statistics/Data Analysis da Stata Corp., Texas, USA, que obteve os resultados pelo método de maximização de esperança (expectation-maximization - EM) para estimar os modelos. (para mais detalhes, ver Greene, 1997, especialmente os capítulos 4 e 5).

O STATA $^{\text {tm }} 9.0$ disponibiliza os resultados do teste de razão de verossimilhança (likelihoodratio test - LR test), que compara os modelos de regressão ordinária e de efeitos aleatórios de intercepto e de inclinação. O teste indica o modelo mais adequado e o software adverte que se trata de um teste conservador, fornecido apenas para referência. Ainda assim, julgamos mais adequado considerar a presença de efeitos aleatórios característicos de modelos multiníveis garantida apenas quando indicado pelo teste, dadas as limitações de nossa base de dados e os problemas de convergência encontrados. Para mais detalhes sobre esse e sobre outros testes assintóticos equivalentes, ver Greene (op. cit)., especialmente o capítulo 4.

\subsection{Descrição e análise dos resultados}

Foram efetivamente comentados os resultados obtidos em 5 (cinco) regressões. Outras foram descartadas, em virtude das limitações impostas pela necessidade de convergência dos modelos, que nem sempre ocorreu. De acordo com o manual do software utilizado, o STATA $^{\mathrm{tm}}$ 9.0, isso pode ocorrer por duas razões básicas: problemas de identificação nos modelos ou variâncias próximas de zero. Assim, ficamos com uma regressão multinível para os municípios (modelo 1) e quatro regressões em painel para os Estados (modelos 2 a 6). Elas estão apresentadas em detalhes no Apêndice 3. As regressões para os Estados consideram apenas variáveis observadas em nível estadual. As regressões multinível do tipo probit, embora com resultados homogêneos e consistentes entre si, e com os demais modelos, quando esses resultados são observados nos municípios, apresentaram resultados inconsistentes com as demais regressões para os Estados. Essas regressões não serão discutidas, mas estão disponíveis com os autores. Conforme vimos, os tempos de espera do modelo $M / M / 1$ são o dobro dos obtidos no $M / D / 1$. Mas ao restringirmos as amostras para tempos de espera menor do que três dias, ficamos com amostras diferentes em cada modelo. Ainda assim, os resultados são qualitativamente quase idênticos e serão comentados em conjunto. O teste L-R (likelihood-ratio test - LR test) apontou um modelo multinível com amostra restrita, ou seja, no qual os tempos de espera são menores do que 3 dias $\left(\mathrm{W}_{\mathrm{q}}<3\right.$ dias) e com efeitos aleatórios nos Estados, como o mais adequado para os municípios. Esse modelo, que será denominado de modelo 1, não considera nenhuma variável em nível estadual como significativa para explicar os tempos de espera nas filas dos municípios. Os modelos para amostra irrestrita apresentam apenas o ano de observação como variável significativa, com sinal positivo, e não merecerão maiores comentários. O modelo em painel, para os Estados, que considera os tempos de espera irrestritos, obtidos no modelo $\mathrm{M} / \mathrm{M} / 1$, como variável dependente será o modelo 2. O modelo 3 considera apenas os tempos de espera menores do que 3 dias ( $\mathrm{W}_{\mathrm{q}}<3$ dias) desse mesmo modelo. $\mathrm{O}$ modelo 4 considera os tempos de espera irrestritos obtidos no modelo $\mathrm{M} / \mathrm{D} / 1$ e o modelo 5 considera os tempos de espera restritos ( $\mathrm{W}_{\mathrm{q}}<3$ dias) no mesmo modelo. Apenas os principais resultados são comentados a seguir. Maiores detalhes sobre as regressões são apresentados no Apêndice 3 do texto.

\section{Fatores de risco materno:}

1. Número de nascimentos com baixo peso (menor do que 2,500 kg) dividido pelo número de partos: com os dados observados nos municípios, essa variável foi significativa, com o sinal positivo esperado. Assim, a presença de baixo peso nos municípios está associada positiva- 
mente com o tempo de espera nas filas, e os Estados da Federação exercem efeitos aleatórios específicos sobre os respectivos municípios. O baixo peso ao nascer não foi significativo para explicar as filas nos Estados.

2. Número de cesarianas dividido pelo número de partos: quando observada nos municípios essa variável foi significativa, com sinal positivo. Assim, a porcentagem de cesarianas em um município estaria positivamente associada com os tempos de espera nas filas, existindo efeitos dos Estados sobre os municípios que os compõem. Essa variável não foi significativa para explicar as filas nos Estados.

3. Número de partos sem consultas de pré-natal dividido pelo número de partos: nos municípios, essa variável foi significativa, com sinal positivo, conforme o esperado. Existiria, portanto, evidência de associação positiva entre o prazo de espera nas filas e a não realização de exames pré-natal nos municípios, com os efeitos aleatórios dos Estados sobre os municípios. Essa variável também foi significativa, com sinal positivo, em todos os modelos em painel para os Estados. Não se pode, portanto, descartar a evidência de que a não realização de exames do tipos pré-natal aumenta o tempo de espera por atendimento para os eventos do capitulo XV da CID-10 no SUS.

4. Número de partos com número realizado de exames pré-natal maior do que sete, dividido pelo número de partos: ao ser observada nos municípios, essa variável foi significativa, com o esperado sinal negativo. Assim, em nível municipal, não se pode descartar uma associação negativa entre a realização de mais do que sete exames do tipo pré-natal e a duração das filas. Os Estados exercem efeitos aleatórios sobre os municípios que a eles pertencem. Essa variável não adquiriu significância estatística para explicar as filas nos Estados.

\section{Fatores assistenciais:}

5. Número de médicos obstetras dividido pelo número de internações: essa variável não obteve significância estatística nos modelos considerados. Conforme comentamos anteriormente, trata-se de variável cujo sentido de atuação sobre as filas não é muito claro.

6. Número de enfermeiros (com nível superior) dividido pelo número de internações: ao ser observada nos municípios, essa variável foi significativa, com o esperado sinal negativo e com efeitos aleatórios dos Estados sobre os municípios. Quanto maior o número de enfermeiros, menor o tempo de espera nas filas nos municípios, e essa influência varia entre os Estados de cada município. Essa variável não foi significativa para explicar as filas nos Estados.

7. Despesa total com saúde por habitante: essa variável, ao ser observada nos municípios, não foi estatisticamente significativa para explicar as filas. Nos Estados, essa variável foi significativa com sinal negativo no modelo 3 e no modelo 5, ou seja, nos modelos de amostra restrita $\left(\mathrm{W}_{\mathrm{q}}<3\right.$ dias $)$. Assim, não se pode descartar a evidência de que o aumento dos gastos com saúde por habitante reduz as filas por atendimento nos Estados. Mas não podemos dizer o mesmo no que se refere aos municípios.

8. Coeficiente de importação de internações: em nível dos municípios, essa variável foi estatisticamente significativa e com o esperado sinal positivo. Assim, não se pode descartar a hipótese de que o atendimento de um número de casos maior do que o número de residentes aumenta as filas nos municípios. Vale observar que, com a exceção de Salvador, no ano de 1999, todas as capitais dos Estados apresentam sempre valores positivos para essa variável. As capitais teriam suas responsabilidades aumentadas por importar casos de outros municípios. Quando observada nos Estados, essa variável foi significativa, também com sinal positivo, no modelo 5 (que utiliza os resultados do modelo $\mathrm{M} / \mathrm{D} / 1 \mathrm{com}$ amostra restrita). Assim, também não se pode descartar a evidência de que a importação líquida de internações pelos Estados esteja positivamente relacionada com a espera nas filas nos Estados. 


\section{Fatores de risco social:}

9. Índice de Desenvolvimento Humano - IDH (ano 2000). Ao ser observado nos municípios, o IDH foi significativo, com sinal positivo, o contrário do esperado. A oferta de serviços de média e de alta complexidade no SUS, nas regiões mais desenvolvidas do País, já verificado na literatura (por exemplo, em Marinho et al., 2001) incrementa a demanda pelos serviços do sistema. O maior nível educacional dos residentes nessas regiões também deve incrementar essa demanda. Quando observada nos Estados, a variável IDH foi estatisticamente significativa, para explicar as filas nos municípios, também com sinal positivo, no modelo 3.

10. Taxa de fecundidade total: nos municípios, essa variável foi significativa, com o esperado sinal positivo. Não se pode, portanto, descartar a correlação positiva entre a taxa de fecundidade nos municípios e os tempos de espera nas filas nos municípios, com efeitos aleatórios dos Estados sobre os municípios. Essa variável não foi significativa para explicar as filas nos Estados.

\section{CONSIDERAÇÕES FINAIS}

Os eventos relacionados ao parto são considerados urgências médicas. (ver MS, 2001). O tempo médio de espera calculado no modelo foi em torno de 20 horas. Esse tempo inclui outros procedimentos que não o parto, mas inclui valores que atingem mais do que 24 horas ou meso 48 horas. Aparentemente, a situação é séria, notando-se, além de tempos de espera elevados, consideráveis discrepâncias de desempenho no SUS. Porém as as razoáveis sensibilidades (elasticidades) das filas permitem inferir ganhos potenciais significativos no sistema. Por outro lado, a redução das discrepâncias e a melhoria do desempenho global do sistema transcendem as capacidades isoladas de ação em nível municipal, requerendo a atuação efetiva de esquemas de coordenação em níveis superiores aos municípios isolados.

O pertencimento a um determinado Estado exerce influência sobre as filas nos municípios, embora variáveis observadas apenas em nível dos Estados não exerçam influência direta sobre as filas estimadas na esfera municipal. Por sua vez, as filas nos Estados são determinadas apenas por variáveis observadas em nível dos Estados. Existiria uma necessidade de priorização de ações locais (municipais) coordenadas em nível estadual no SUS. Destacam-se, entre essas ações, a realização de mais de sete exames do tipo pré-natal e a presença de enfermeiros de nível superior. Nos Estados, não se pode descartar a evidência de que o aumento das despesas com saúde por habitante reduz os tempos de espera nas filas. Nos municípios, a presença de nascituros com baixo peso, elevadas porcentagem de cesarianas, a não realização de exames pré-natais (essa também observada nos Estados), a elevação da taxa de fecundidade total e a elevação do coeficiente de importação de internações (também constatada nos Estados) são fenômenos que aumentam o tempo de espera nas filas. A falta de presteza de atendimento relacionado com o capítulo XV da CID-10 deveria ser objeto de maiores investigações no âmbito do Sistema Único de Saúde - SUS. 


\section{APÊNDICE 1 - CID-10 - ClASSIFICAÇÃo ESTATÍSTICA INTERNACIONAL DE DOENÇAS E PROBLEMAS RELACIONADOS À SAÚDE}

\section{Capítulo XV - Gravidez, parto e puerpério (O00-O99)}

O00-O08 Gravidez que termina em aborto

O00 Gravidez ectópica

O01 Mola hidatiforme

O02 Outros produtos anormais da concepção

O03 Aborto espontâneo

O04 Aborto por razões médicas e legais

O05 Outros tipos de aborto

O06 Aborto não especificado

O07 Falha de tentativa de aborto

O08 Complicações conseqüentes a aborto e gravidez ectópica ou molar

O10-O16 Edema, proteinúria e transtornos hipertensivos na gravidez, no parto e no puerpério

O10 Hipertensão pré-existente complicando a gravidez, o parto e o puerpério

O11 Distúrbio hipertensivo pré-existente com proteinúria superposta

O12 Edema e proteinúria gestacionais [induzidos pela gravidez], sem hipertensão

O13 Hipertensão gestacional [induzida pela gravidez] sem proteinúria significativa

O14 Hipertensão gestacional [induzida pela gravidez] com proteinúria significativa

O15 Eclâmpsia

O16 Hipertensão materna não especificada

O20-O29 Outros transtornos maternos relacionados predominantemente com a gravidez

O20 Hemorragia do início da gravidez

O21 Vômitos excessivos na gravidez

O22 Complicações venosas na gravidez

O23 Infecções do trato geniturinário na gravidez

O24 Diabetes mellitus na gravidez

O25 Desnutrição na gravidez

O26 Assistência materna por outras complicações ligadas predominantemente à gravidez

O28 Achados anormais do rastreamento ["screening"] antenatal da mãe

O29 Complicações de anestesia administrada durante a gravidez

O30-O48 Assistência prestada à mãe por motivos ligados ao feto e à cavidade amniótica e por possíveis problemas relativos ao parto

O30 Gestação múltipla

O31 Complicações específicas de gestação múltipla

O32 Assistência prestada à mãe por motivo de apresentação anormal, conhecida ou suspeitada, do feto

O33 Assistência prestada à mãe por uma desproporção conhecida ou suspeita

O34 Assistência prestada à mãe por anormalidade, conhecida ou suspeita, dos órgãos pélvicos maternos

O35 Assistência prestada à mãe por anormalidade e lesão fetais, conhecidas ou suspeitadas

O36 Assistência prestada à mãe por outros problemas fetais conhecidos ou suspeitados

O40 Polihidrâmnio

O41 Outros transtornos das membranas e do líquido amniótico

O42 Ruptura prematura de membranas

O43 Transtornos da placenta 
O44 Placenta prévia

O45 Descolamento prematuro da placenta [abruptio placentae]

O46 Hemorragia anteparto não classificada em outra parte

O47 Falso trabalho de parto

O48 Gravidez prolongada

O60-075 Complicações do trabalho de parto e do parto

O60 Parto pré-termo

O61 Falha na indução do trabalho de parto

O62 Anormalidades da contração uterina

O63 Trabalho de parto prolongado

O64 Obstrução do trabalho de parto devida à má-posição ou má-apresentação do feto

O65 Obstrução do trabalho de parto devida a anormalidade pélvica da mãe

O66 Outras formas de obstrução do trabalho de parto

O67 Trabalho de parto e parto complicados por hemorragia intraparto não classificados em outra parte

O68 Trabalho de parto e parto complicados por sofrimento fetal

O69 Trabalho de parto e parto complicados por anormalidade do cordão umbilical

O70 Laceração do períneo durante o parto

O71 Outros traumatismos obstétricos

O72 Hemorragia pós-parto

O73 Retenção da placenta e das membranas, sem hemorragias

O74 Complicações de anestesia durante o trabalho de parto e o parto

O75 Outras complicações do trabalho de parto e do parto não classificadas em outra parte

\section{O80-O84 Parto}

O80 Parto único espontâneo

O81 Parto único por fórceps ou vácuo-extrator

O82 Parto único por cesariana

O83 Outros tipos de parto único assistido

O84 Parto múltiplo

O85-O92 Complicações relacionadas predominantemente com o puerpério

O85 Infecção puerperal

O86 Outras infecções puerperais

O87 Complicações venosas no puerpério

O88 Embolia de origem obstétrica

O89 Complicações da anestesia administrada durante o puerpério

O90 Complicações do puerpério não classificadas em outra parte

O91 Infecções mamárias associadas ao parto

O92 Outras afecções da mama e da lactação associadas ao parto

O95-O99 Outras afecções obstétricas não classificadas em outra parte

O95 Morte obstétrica de causa não especificada

O96 Morte, por qualquer causa obstétrica, que ocorre mais de 42 dias, mas menos de 1 ano, após o parto O97 Morte por seqüelas de causas obstétricas diretas

O98 Doenças infecciosas e parasitárias maternas classificáveis em outra parte mas que compliquem a gravidez, o parto e o puerpério

O99 Outras doenças da mãe, classificadas em outra parte, mas que complicam a gravidez o parto e o puerpério 


\section{APÊNDICE 2 - As FILAS NOS ESTADOS E NAS CAPITAIS}

Legenda: $\mathrm{W}_{\mathrm{q}}$ : tempo médio esperado na fila no modelo $M / M / 1$.

$\mathrm{W}_{\mathrm{q}} / 2$ : tempo médio esperado na fila no modelo $M / D / 1$.

W: tempo total de espera no SUS (inclui o tratamento e as filas).

$\mathrm{U}$ : probabilidade de que todos os leitos estejam ocupados.

\begin{tabular}{|c|c|c|c|c|c|}
\hline \multicolumn{6}{|c|}{ Ano: 1999} \\
\hline Unidade da Federação & $\mathrm{Wq}$ & Wq & U & $\mathrm{Wq} / 2$ & $\mathrm{Wq} / 2$ \\
\hline & (Dias) & (Horas) & & (Dias) & (Horas) \\
\hline Acre & 12,266 & 294,375 & 0,763 & 6,133 & 147,188 \\
\hline Alagoas & 1,349 & 32,386 & 0,391 & 0,675 & 16,193 \\
\hline Amapá & 2,869 & 68,852 & 0,544 & 1,434 & 34,426 \\
\hline Amazonas & 1,297 & 31,129 & 0,382 & 0,649 & 15,564 \\
\hline Bahia & 0,841 & 20,189 & 0,286 & 0,421 & 10,094 \\
\hline Ceará & 0,661 & 15,863 & 0,280 & 0,330 & 7,932 \\
\hline Distrito Federal & 24,406 & 585,740 & 0,894 & 12,203 & 292,870 \\
\hline Espírito Santo & 1,467 & 35,216 & 0,370 & 0,734 & 17,608 \\
\hline Goiás & 0,403 & 9,661 & 0,130 & 0,201 & 4,831 \\
\hline Maranhão & 0,580 & 13,910 & 0,182 & 0,290 & 6,955 \\
\hline Mato Grosso & 0,449 & 10,775 & 0,169 & 0,224 & 5,387 \\
\hline Mato Grosso do Sul & 0,466 & 11,175 & 0,181 & 0,233 & 5,587 \\
\hline Minas Gerais & 0,493 & 11,834 & 0,198 & 0,247 & 5,917 \\
\hline Paraná & 0,706 & 16,947 & 0,227 & 0,353 & 8,473 \\
\hline Paraíba & 0,466 & 11,173 & 0,175 & 0,233 & 5,587 \\
\hline Pará & 0,937 & 22,483 & 0,308 & 0,468 & 11,242 \\
\hline Pernambuco & 0,871 & 20,893 & 0,314 & 0,435 & 10,447 \\
\hline Piauí & 0,534 & 12,804 & 0,211 & 0,267 & 6,402 \\
\hline Rio Grande do Norte & 0,859 & 20,625 & 0,264 & 0,430 & 10,312 \\
\hline Rio Grande do Sul & 0,704 & 16,889 & 0,234 & 0,352 & 8,445 \\
\hline Rio de Janeiro & 2,001 & 48,013 & 0,392 & 1,000 & 24,007 \\
\hline Rondônia & 0,828 & 19,872 & 0,283 & 0,414 & 9,936 \\
\hline Roraima & ND & ND & ND & ND & ND \\
\hline Santa Catarina & 1,011 & 24,264 & 0,296 & 0,505 & 12,132 \\
\hline Sergipe & 1,445 & 34,681 & 0,432 & 0,723 & 17,341 \\
\hline São Paulo & 1,169 & 28,059 & 0,319 & 0,585 & 14,030 \\
\hline Tocantins & 0,542 & 13,003 & 0,222 & 0,271 & 6,501 \\
\hline
\end{tabular}

ND: dados não disponíveis. 
(continuação)

\begin{tabular}{|c|c|c|c|c|c|}
\hline \multicolumn{6}{|c|}{ Ano: 2002} \\
\hline Unidade da Federação & Wq & $\mathrm{Wq}$ & U & $\mathrm{Wq} / 2$ & $\mathrm{Wq} / 2$ \\
\hline & (Dias) & (Horas) & & (Dias) & (Horas) \\
\hline Acre & 1,902 & 45,649 & 0,442 & 0,951 & 22,825 \\
\hline Alagoas & 1,180 & 28,331 & 0,371 & 0,590 & 14,165 \\
\hline Amapá & 3,227 & 77,443 & 0,563 & 1,613 & 38,722 \\
\hline Amazonas & 1,427 & 34,254 & 0,416 & 0,714 & 17,127 \\
\hline Bahia & 0,676 & 16,212 & 0,252 & 0,338 & 8,106 \\
\hline Ceará & 0,915 & 21,950 & 0,314 & 0,457 & 10,975 \\
\hline Distrito Federal & 5,552 & 133,259 & 0,657 & 2,776 & 66,629 \\
\hline Espírito Santo & 1,881 & 45,134 & 0,402 & 0,940 & 22,567 \\
\hline Goiás & 0,290 & 6,948 & 0,112 & 0,145 & 3,474 \\
\hline Maranhão & 0,788 & 18,909 & 0,240 & 0,394 & 9,455 \\
\hline Mato Grosso & 0,463 & 11,114 & 0,188 & 0,232 & 5,557 \\
\hline Mato Grosso do Sul & 0,570 & 13,671 & 0,206 & 0,285 & 6,836 \\
\hline Minas Gerais & 0,497 & 11,929 & 0,199 & 0,249 & 5,964 \\
\hline Paraná & 0,554 & 13,284 & 0,194 & 0,277 & 6,642 \\
\hline Paraíba & 0,542 & 12,998 & 0,198 & 0,271 & 6,499 \\
\hline Pará & 0,887 & 21,294 & 0,307 & 0,444 & 10,647 \\
\hline Pernambuco & 1,014 & 24,327 & 0,326 & 0,507 & 12,164 \\
\hline Piauí & 0,760 & 18,243 & 0,233 & 0,380 & 9,121 \\
\hline Rio Grande do Norte & 0,755 & 18,121 & 0,256 & 0,378 & 9,060 \\
\hline Rio Grande do Sul & 0,592 & 14,215 & 0,205 & 0,296 & 7,108 \\
\hline Rio de Janeiro & 1,696 & 40,708 & 0,361 & 0,848 & 20,354 \\
\hline Rondônia & 0,703 & 16,879 & 0,251 & 0,352 & 8,439 \\
\hline Roraima & 1,218 & 29,242 & 0,311 & 0,609 & 14,621 \\
\hline Santa Catarina & 0,930 & 22,319 & 0,271 & 0,465 & 11,160 \\
\hline Sergipe & 1,246 & 29,904 & 0,384 & 0,623 & 14,952 \\
\hline São Paulo & 1,276 & 30,621 & 0,329 & 0,638 & 15,311 \\
\hline Tocantins & 0,715 & 17,171 & 0,284 & 0,358 & 8,585 \\
\hline
\end{tabular}




\section{APÊNDICE 3 - OS MODELOS ECONOMÉTRICOS}

Modelo 1 - Tempo de espera nos municípios: amostra restrita $(\mathrm{Wq}<3)$, modelo $\mathrm{M} / \mathrm{M} / 1$. $\mathrm{Re}$ gressão: modelo com efeitos aleatórios dos Estados

Número de observações $=5935$

Wald chi2 $(21)=473.49$

Log restricted-likelihood $=-4441.6372$.

Prob > chi2 $=0.0000$

\begin{tabular}{|c|c|c|c|c|c|c|}
\hline \multirow[t]{2}{*}{ Tempo médio esperado na fila } & \multirow[t]{2}{*}{ Coeficiente } & \multirow{2}{*}{$\begin{array}{l}\text { Desvio } \\
\text { Padrão }\end{array}$} & \multirow[t]{2}{*}{ Z } & \multirow[t]{2}{*}{$P>|z|$} & \multicolumn{2}{|c|}{ Intervalo de confiança } \\
\hline & & & & & Low & Up \\
\hline Ano & 0,011 & 0,081 & 0,140 & 0,890 & $-0,148$ & 0,171 \\
\hline Baixo peso ao nascer (Estadual) & 0,012 & 0,042 & 0,290 & 0,770 & $-0,070$ & 0,095 \\
\hline Cesariana (Estadual) & $-0,014$ & 0,009 & $-1,560$ & 0,118 & $-0,032$ & 0,004 \\
\hline Despesa total com saúde por habitante (Estadual) & 0,001 & 0,002 & 0,710 & 0,475 & $-0,002$ & 0,005 \\
\hline Índice de Desenvolvimento Humano (Estadual) & $-0,850$ & 0,803 & $-1,060$ & 0,290 & $-2,424$ & 0,724 \\
\hline Taxa de fecundidade total (Estadual) & 0,128 & 0,134 & 0,950 & 0,341 & $-0,135$ & 0,390 \\
\hline $\begin{array}{l}\text { Número de partos sem consultas de pré-natal } \\
\text { dividido pelo número de partos (Estadual) }\end{array}$ & 0,011 & 0,009 & 1,140 & 0,254 & $-0,008$ & 0,029 \\
\hline $\begin{array}{l}\text { Número de partos com número realizado de exames pré-natal } \\
\text { maior do que sete dividido pelo número de partos (Estadual) }\end{array}$ & 0,002 & 0,003 & 0,690 & 0,490 & $-0,004$ & 0,009 \\
\hline Coeficiente de importação de internações (Estadual) & 0,006 & 0,011 & 0,500 & 0,619 & $-0,017$ & 0,028 \\
\hline $\begin{array}{l}\text { Número de médicos gineco-obstetras dividido pelo } \\
\text { número de internações (Estadual) }\end{array}$ & 0,007 & 0,008 & 0,860 & 0,391 & $-0,009$ & 0,023 \\
\hline $\begin{array}{l}\text { Número de enfermeiros (com nível superior) } \\
\text { dividido pelo número de internações (Estadual) }\end{array}$ & $-0,004$ & 0,003 & $-1,010$ & 0,311 & $-0,010$ & 0,003 \\
\hline Baixo peso ao nascer (Municipal) & 0,014 & 0,002 & 6,310 & 0,000 & 0,009 & 0,018 \\
\hline Cesariana (Municipal) & 0,012 & 0,001 & 10,660 & 0,000 & 0,010 & 0,014 \\
\hline Despesa total com saúde por habitante (Municipal) & 0,000 & 0,000 & $-0,740$ & 0,459 & 0,000 & 0,000 \\
\hline Índice de Desenvolvimento Humano (Municipal) & 0,003 & 0,001 & 2,230 & 0,026 & 0,000 & 0,005 \\
\hline Taxa de fecundidade total (Municipal) & $-0,001$ & 0,000 & $-4,200$ & 0,000 & $-0,002$ & $-0,001$ \\
\hline $\begin{array}{l}\text { Número de partos sem consultas de pré-natal } \\
\text { dividido pelo número de partos (Municipal) }\end{array}$ & 1,120 & 0,205 & 5,460 & 0,000 & 0,718 & 1,522 \\
\hline $\begin{array}{l}\text { Número de partos com número realizado de exames pré-natal } \\
\text { maior do que sete dividido pelo número de partos (Municipal) }\end{array}$ & 0,117 & 0,017 & 7,080 & 0,000 & 0,085 & 0,149 \\
\hline Coeficiente de importação de internações (Municipal) & 0,002 & 0,000 & 8,450 & 0,000 & 0,001 & 0,002 \\
\hline $\begin{array}{l}\text { Número de médicos gineco-obstetras } \\
\text { dividido pelo número de internações (Municipal) }\end{array}$ & 0,000 & 0,000 & $-0,780$ & 0,438 & 0,000 & 0,000 \\
\hline $\begin{array}{l}\text { Número de enfermeiros (com nível superior) } \\
\text { dividido pelo número de internações (Municipal) }\end{array}$ & 0,000 & 0,000 & $-3,170$ & 0,002 & 0,000 & 0,000 \\
\hline Constante & $-0,517$ & 0,620 & $-0,830$ & 0,404 & $-1,731$ & 0,697 \\
\hline
\end{tabular}


(continuação)

Modelo de efeitos fixos vs. Modelo clássico

Modelo de efeitos aleatórios do tempo vs. Modelo clássico

Modelo de efeitos aleatórios do tempo vs. Modelo de efeitos fixos

Modelo de efeitos aleatórios da UF vs. Modelo clássico

Modelo de efeitos aleatórios do UF vs. Modelo de efeitos fixos

$$
\begin{aligned}
& \text { chi2 }(3)=114.18 \text { Prob }>\text { chi } 2=0.0000 \\
& \text { chi2 } 24)=121.19 \text { Prob }>\text { chi } 2=0.0000 \\
& \text { chi2 } 21)=7.01 \quad \text { Prob }>\text { chi } 2=0.9981 \\
& \text { chi2 } 24)=171.36 \text { Prob }>\text { chi } 2=0.0000 \\
& \text { chi2 } 21)=57.18 \text { Prob }>\text { chi } 2=0.0000
\end{aligned}
$$

\section{Modelo 2 - Tempo de espera nos Estados: amostra irrestrita, modelo M/M/1. Regressão: re-} gressão linear, modelo clássico

Número de observações $=51$

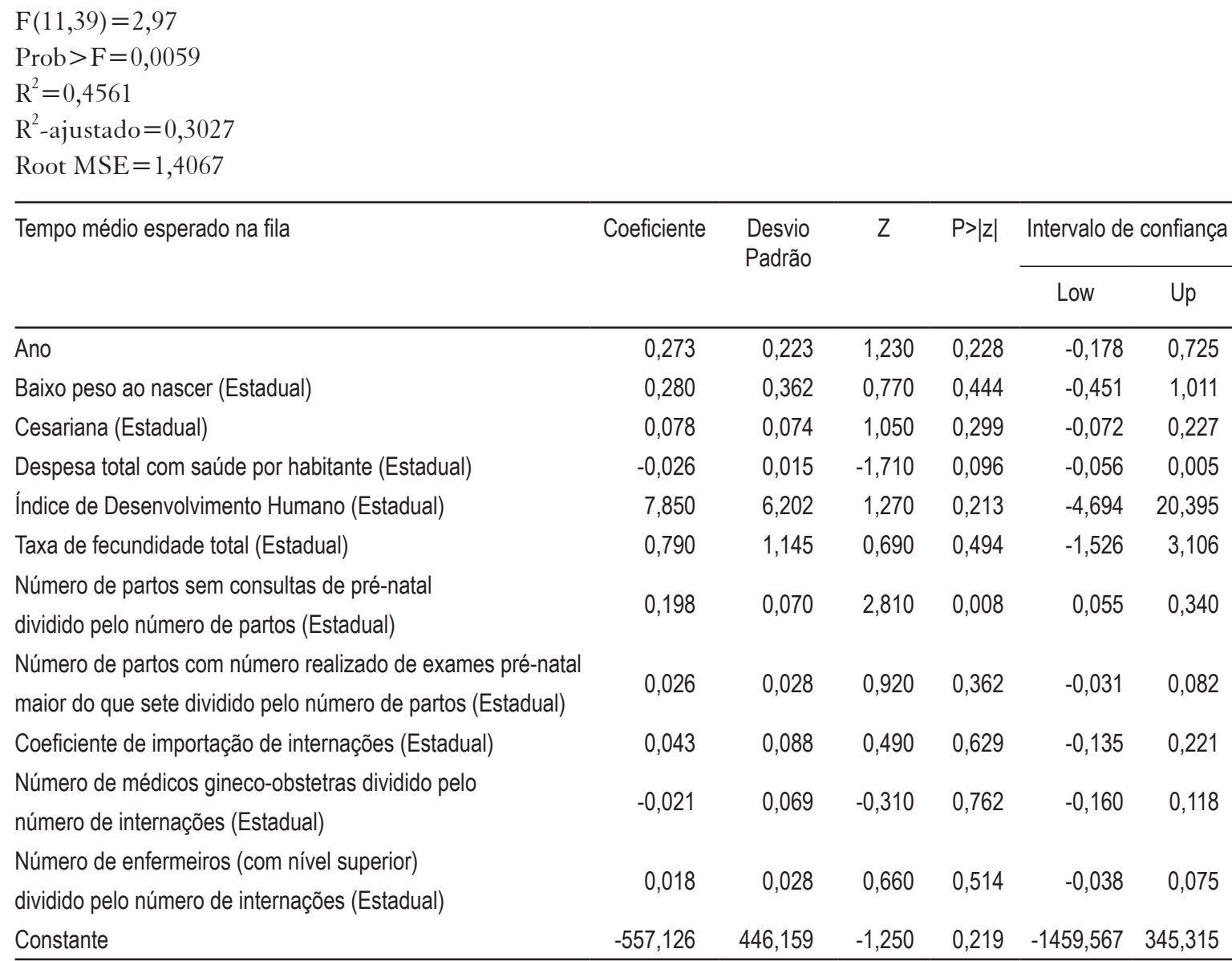

Modelo de efeitos fixos vs. Modelo clássico

Modelo de efeitos aleatórios do tempo vs. Modelo clássico

Modelo de efeitos aleatórios do tempo vs. Modelo de efeitos fixos

$$
\begin{array}{ll}
\operatorname{chi} 2(2)=0.00 & \text { Prob }>\text { chi } 2=1.0000 \\
\operatorname{chi} 2(13)=1.90 & \text { Prob }>\text { chi } 2=0.9998 \\
\operatorname{chi} 2(11)=1.90 & \text { Prob }>\text { chi } 2=0.9988
\end{array}
$$


Modelo 3 - Tempo de espera nos Estados: amostra restrita $(\mathrm{Wq}<3)$, modelo $\mathrm{M} / \mathrm{M} / 1$. Regressão: regressão linear, modelo clássico

Número de observações $=49$

$\mathrm{F}(11,39)=4,87$

Prob $>\mathrm{F}=0,0001$

$\mathrm{R}^{2}=0,5915$

$\mathrm{R}^{2}$-ajustado $=0,4701$

Root MSE $=0,36749$

\begin{tabular}{llllll}
\hline Tempo médio esperado na fila & Coeficiente & $\begin{array}{l}\text { Desvio } \\
\text { Padrão }\end{array}$ & $Z$ & $P>|z|$ & \begin{tabular}{c} 
Intervalo de confiança \\
\cline { 2 - 4 }
\end{tabular}
\end{tabular}

\begin{tabular}{lrrrrrr}
\hline Ano & 0,09 & 0,06 & 1,53 & 0,13 & $-0,03$ & 0,21 \\
Baixo peso ao nascer (Estadual) & $-0,02$ & 0,10 & $-0,23$ & 0,82 & $-0,22$ & 0,18 \\
Cesariana (Estadual) & $-0,02$ & 0,02 & $-1,11$ & 0,27 & $-0,06$ & 0,02 \\
Despesa total com saúde por habitante (Estadual) & $-0,01$ & 0,00 & $-2,05$ & 0,05 & $-0,02$ & 0,00 \\
$\begin{array}{l}\text { Índice de Desenvolvimento Humano (Estadual) } \\
\text { Taxa de fecundidade total (Estadual) }\end{array}$ & 5,21 & 1,73 & 3,01 & 0,01 & 1,70 & 8,71 \\
$\begin{array}{l}\text { Número de partos sem consultas de pré-natal } \\
\text { dividido pelo número de partos (Estadual) }\end{array}$ & 0,60 & 0,30 & 2,00 & 0,05 & $-0,01$ & 1,20 \\
Número de partos com número realizado de exames pré-natal & 0,05 & 0,02 & 2,32 & 0,03 & 0,01 & 0,09 \\
maior do que sete dividido pelo número de partos (Estadual) & 0,00 & 0,01 & 0,62 & 0,54 & $-0,01$ & 0,02 \\
Coeficiente de importação de internações (Estadual) & 0,05 & 0,02 & 1,96 & 0,06 & 0,00 & 0,09 \\
$\begin{array}{l}\text { Número de médicos gineco-obstetras dividido pelo } \\
\text { número de internações (Estadual) }\end{array}$ & 0,03 & 0,02 & 1,58 & 0,12 & $-0,01$ & 0,07 \\
$\begin{array}{l}\text { Número de enfermeiros (com nível superior) } \\
\text { dividido pelo número de internações (Estadual) }\end{array}$ & 0,01 & 0,01 & 0,95 & 0,35 & $-0,01$ & 0,02 \\
Constante & $-187,29$ & 119,49 & $-1,57$ & 0,13 & $-429,40$ & 54,83 \\
\hline
\end{tabular}

Modelo de efeitos fixos vs. Modelo clássico

$\operatorname{chi} 2(2)=0.00 \quad$ Prob $>$ chi2 $=1.0000$

Modelo de efeitos aleatórios do tempo vs. Modelo clássico

$\operatorname{chi} 2(13)=0.00$ Prob $>$ chi $2=1.0000$

Modelo de efeitos aleatórios do tempo vs. Modelo de efeitos fixos

$\operatorname{chi} 2(11)=-0.22$ Prob $>$ chi $2=1.0000$ 
Modelo 4 - Tempo de espera nos Estados: amostra irrestrita, modelo M/D/1 (Wq/2). Regressão: regressão linear, modelo clássico

Número de observações $=51$

$\mathrm{F}(11,39)=2,97$

Prob $>\mathrm{F}=0,0059$

$\mathrm{R}^{2}=0,4561$

$\mathrm{R}^{2}$-ajustado $=0,3027$

Root MSE $=0,70337$

\begin{tabular}{lcccccc}
\hline Tempo médio esperado na fila & Coeficiente & $\begin{array}{c}\text { Desvio } \\
\text { Padrão }\end{array}$ & & P $>|z|$ & Intervalo de confiança \\
\cline { 5 - 7 } & & & & & Low & Up \\
\hline Ano & & & & & & \\
Baixo peso ao nascer (Estadual) & 0,137 & 0,112 & 1,230 & 0,228 & $-0,089$ & 0,362 \\
Cesariana (Estadual) & 0,140 & 0,181 & 0,770 & 0,444 & $-0,226$ & 0,506 \\
Despesa total com saúde por habitante (Estadual) & 0,039 & 0,037 & 1,050 & 0,299 & $-0,036$ & 0,114 \\
Índice de Desenvolvimento Humano (Estadual) & $-0,013$ & 0,007 & $-1,710$ & 0,096 & $-0,028$ & 0,002 \\
Taxa de fecundidade total (Estadual) & 3,925 & 3,101 & 1,270 & 0,213 & $-2,347$ & 10,198 \\
Número de partos sem consultas de pré-natal & 0,395 & 0,572 & 0,690 & 0,494 & $-0,763$ & 1,553 \\
dividido pelo número de partos (Estadual) & 0,099 & 0,035 & 2,810 & 0,008 & 0,028 & 0,170 \\
Número de partos com número realizado de exames pré-natal & & & & & & \\
maior do que sete dividido pelo número de partos (Estadual) & 0,013 & 0,014 & 0,920 & 0,362 & $-0,015$ & 0,041 \\
Coeficiente de importação de internações (Estadual) & 0,021 & 0,044 & 0,490 & 0,629 & $-0,068$ & 0,110 \\
Número de médicos gineco-obstetras dividido pelo & $-0,010$ & 0,034 & $-0,310$ & 0,762 & $-0,080$ & 0,059 \\
número de internações (Estadual) & & & & & & \\
Número de enfermeiros (com nível superior) & 0,009 & 0,014 & 0,660 & 0,514 & $-0,019$ & 0,038 \\
dividido pelo número de internações (Estadual) & $-278,563$ & 223,079 & $-1,250$ & 0,219 & $-729,784$ & 172,658 \\
\hline Constante & & & & & &
\end{tabular}

Modelo de efeitos fixos vs. Modelo clássico

Modelo de efeitos aleatórios do tempo vs. Modelo clássico

Modelo de efeitos aleatórios do tempo vs. Modelo de efeitos fixos

\author{
$\operatorname{chi} 2(2)=0.00 \quad$ Prob $>\operatorname{chi} 2=1.0000$ \\ $\operatorname{chi} 2(13)=1.90$ Prob $>$ chi2 $=0.9998$ \\ chi2 $(11)=1.90$ Prob $>$ chi2 $=0.9988$
}


Modelo 5 - Tempo de espera nos Estados: amostra restrita, modelo M/D/1 ([Wq/2]<3). Regressão: regressão linear, modelo clássico

Número de observações $=50$

$$
\begin{aligned}
& \mathrm{F}(11,39)=7,35 \\
& \text { Prob }>\mathrm{F}=0,0000 \\
& \mathrm{R}^{2}=0,6802 \\
& \mathrm{R}^{2} \text {-ajustado=0,5876 }
\end{aligned}
$$

\begin{tabular}{lrrrrrr}
\hline Tempo médio esperado na fila & Coeficiente & $\begin{array}{c}\text { Desvio } \\
\text { Padrão }\end{array}$ & & P $>|z|$ & Intervalo de confiança \\
\cline { 5 - 7 } & & & & Low & Up \\
\hline Ano & & & & & & \\
Baixo peso ao nascer (Estadual) & 0,057 & 0,030 & 1,860 & 0,071 & $-0,005$ & 0,118 \\
Cesariana (Estadual) & 0,012 & 0,049 & 0,240 & 0,808 & $-0,088$ & 0,112 \\
Despesa total com saúde por habitante (Estadual) & $-0,013$ & 0,010 & $-1,290$ & 0,204 & $-0,034$ & 0,008 \\
Índice de Desenvolvimento Humano (Estadual) & $-0,004$ & 0,002 & $-2,060$ & 0,046 & $-0,008$ & 0,000 \\
Taxa de fecundidade total (Estadual) & 3,210 & 0,842 & 3,810 & 0,000 & 1,505 & 4,916 \\
Número de partos sem consultas de pré-natal & 0,309 & 0,155 & 1,990 & 0,054 & $-0,006$ & 0,623 \\
dividido pelo número de partos (Estadual) & 0,026 & 0,010 & 2,590 & 0,014 & 0,006 & 0,047 \\
Número de partos com número realizado de exames pré-natal & & & & & & \\
maior do que sete dividido pelo número de partos (Estadual) & 0,001 & 0,004 & 0,320 & 0,752 & $-0,007$ & 0,009 \\
Coeficiente de importação de internações (Estadual) & 0,026 & 0,012 & 2,140 & 0,039 & 0,001 & 0,050 \\
Número de médicos gineco-obstetras dividido pelo & 0,013 & 0,009 & 1,390 & 0,173 & $-0,006$ & 0,032 \\
número de internações (Estadual) & & & & & & \\
Número de enfermeiros (com nível superior) & 0,002 & 0,004 & 0,560 & 0,576 & $-0,006$ & 0,010 \\
dividido pelo número de internações (Estadual) & $-115,961$ & 60,998 & $-1,900$ & 0,065 & $-239,446$ & 7,523 \\
\hline Contante & & & & &
\end{tabular}

Modelo de efeitos fixos vs. Modelo clássico

Modelo de efeitos aleatórios do tempo vs. Modelo clássico

Modelo de efeitos aleatórios do tempo vs. Modelo de efeitos fixos

$$
\begin{array}{ll}
\text { chi2 } 2(2) & =0.00 \text { Prob }>\text { chi2 }=1.0000 \\
\operatorname{chi} 2(13) & =0.00 \text { Prob }>\text { chi } 2=1.0000 \\
\operatorname{chi} 2(11) & =-0.09 \text { Prob }>\text { chi } 2=1.0000
\end{array}
$$




\section{REFERÊNCIAS BIBLIOGRÁFICAS}

ACKERE A. VAN.; SMITH, P. C. A dinamic model of national health service waiting lists. Systems Dynamic Groups, WP-0026, Mar. 1999.

ALMEIDA, M. F. Partos domiciliares acidentais na região sul do município de São Paulo. Revista de Saúde Pública, v. 39, n. 3, p. 366-375, 2005.

BALE, J. R.; STOLL, B. J.; ADETOKUNBO, O. L. (eds.). COMMITTEE ON IMPROVING BIRTH OUTCOMES, BOARD ON GLOBAL HEALTH. Improving Birth Outcomes; Meeting the Challenge in the Developing World. The National Academic Press, Washington, DC, 2003.

COUTINHO, T.; TEIXEIRA, M. T. B.; DAIN, S.; SAYD, J. D.; COUTINHO, L. M. Adequação do processo de assistência pré-natal entre as usuárias do Sistema Único de Saúde em Juiz de Fora - MG. Revista Brasileira de Ginecologia e Obstetrícia - RBGO, v. 25, n. 10, p. 717-724, 2003.

COX, R. D.; SMITH, W. L. Queues. London and Colchester: Spottiswoode, Ballantyne \& Co. Ltd., 1961.

CULLIS, J. G.; JONES, P. R.; PROPPER, C. Waiting lists and medical care treatment: analysis and policies. In: CULYER, A. J.; NEWHOUSE, J. P. (eds.). Handbook of health economics, v. 1B. Amsterdam: Elsevier-North-Holland, 2000. p. 1201-1249.

FURUKUBO, M.; OHUCHI, A.; KUROKAWA, T. Analysis of the congestion of medical care centers. In: FIFTH CONFERENCE OF THE ASSOCIATION OF ASIAN-PACIFIC OPERATIONS RESEARCH SOCIETY, Singapore, July 2000. Disponível em: http://www.ise.nus.edu.sg/proceedings/apors2000/ fullpapers/13-04-fp.htm. Acesso em: 31 out. 2002.

GOLDSTEIN, H. Multilevel statistical models. Kendall's Library of Statistics 3. Edward Arnold, $2^{\text {nd }}$ ed., 1995.

GREEN, L. V. Capacity planning and management in hospitals. In: Brandeau, M. L.; Sainfort, F.; Pierskalla, W. P. (eds.). Operations research and health care. a handbook of methods and applications. MA, USA: Kluwer Academic Publishers, p. 15-41, 2004.

GREENE, W. H. Econometric analysis. $3^{\text {rd }}$ ed. N. J.: Prentice-Hall, Inc., 1997.

GROSS, D.; HARRIS, C. M. Fundamentals of queueing theory. $3^{\text {rd }}$ ed. N.Y: John Wiley \& Sons, 1998.

HILLIER, S. F.; LIEBERMAN, G. J. Introduction to operations research. $6^{\text {th }}$ ed. Singapore: McGraw-Hill Book Co., 1995.

HOEL, M.; SAETHER, M. E. Public health care with waiting time: the role of supplementary private health care. Journal of Health Economics, v. 22, p. 599-616, 2003.

IVERSEN, T. An Interaction Model of Public and Private Health Services: Surgical Waiting Lists. In: Culyer, A. J.; Jonsson, B. (eds.). Public and private health services. Oxford: Basil Blackwell, p. 131-151, 1986.

. A theory of hospital waiting lines. Journal of Health Economics, v. 12, p. 55-71, 1993.

. The effect of a private sector on the waiting time in a national health service. Journal of Health Economics, v. 16, n. 4, p. 381-396, Aug. 1997.

JOHANNENSSON, M.; JOHANSSON, P-O.; SÖDERQVIST, T. Time spent on waiting lists for medical care: an insurance approach. Journal of Health Economics, v. 17, p. 627-644, 1998.

JONES, A. M., Health econometrics, In: CULYER, A. J.; NEWHOUSE, J. P. (eds.). Handbook of health economics. v. 1A. Amsterdam: Elsevier-North-Holland, 2000. p. 267-344.

LILLIEFORS, H. W. Some confidence intervals for queues. Operations Research, v. 14, n. 4, Jul.-Aug., p. 723-727, 1966.

MANGO, P. D.; SHAPIRO, L. A. Hospitals get serious about operations. The McKinsey Quarterly, n. 2, p. 74-85, 2001. 
MARINHO, A. Um estudo sobre as filas para internações e para transplantes no Sistema Único de Saúde brasileiro. Instituto de Pesquisa Econômica Aplicada - IPEA, nov. 2004. (Texto para Discussão, n. 1055).

Um estudo sobre as filas para transplantes no Sistema Único de Saúde brasileiro. Cadernos de Saúde Pública, v. 22, n. 10, p. 2.229-2.239, out. 2006.

.; MORENO, A.; CAVALINI, L. T. Avaliação descritiva da rede hospitalar do Sistema Único de Saúde (SUS). Instituto de Pesquisa Econômica Aplicada - IPEA, dez. 2001. (Texto para Discussão n. 848).

MENEZES, D. C. S., LEITE, C. I., SCHRAMM, J. M. A ., LEAL, M. C. Avaliação da peregrinação anteparto numa amostra de puérperas no Município do Rio de Janeiro, Brasil, 1999/2001. Cadernos de Saúde Pública, v. 22, n. 3, p. 553-559, mar. 2006.

OR, Z.; WANG, J.; JAMISON, D. International differences in the impact of doctors on health: a multilevel analysis of OECD countries. Journal of Health Economics, v. 24, p. 531-560, 2005.

MINISTÉRIO DA SAÚDE - MS. Parto, aborto e puerpério. Assistência humanizada à mulher. Secretaria de Políticas de Saúde, Área Técnica de Saúde da Mulher, Brasília - DF, 2001.

PANICO, J. A. Queueing theory. A study of waiting lines for business, economics and science. New Jersey, U.S.A: Prentice-Hall, Inc., Englewood Cliffs, 1969.

RODRÍGUEZ, G.; GOLDMAN, N. Improved estimation procedures for multilevel models with binary response: a case study. Journal of the Royal Statistical Society, A., 164 part 2, p. 339-355, 2001.

SCHRAMM, J. M. A.; SWARCWALD, C. L.; ESTEVES, M. A. P. Assistência obstétrica e risco de internação na rede de hospitais do Estado do Rio de Janeiro. Revista de Saúde Pública, v. 36, n. 5, p. 590-597, 2002.

SICILIANI, L.; HURST, J. Explaining waiting times variations for elective surgery across OECD countries. Oct. 2003. (OECD Health Working Papers, n. 7).

SILVA, K. S. Mortalidade materna: avaliação da situação no Rio de Janeiro, no período de 1997 a 1987. Cadernos de Saúde Pública, v. 8, n. 4, p. 442-453, out./dez. 1992.

SILVEIRA, D. S.; SANTOS, I. S. Fatores associados à cesariana entre mulheres de baixa renda em Pelotas, Rio Grande do Sul, Brasil. Cadernos de Saúde Pública, 20 Sup 2: s231-s241, 2004(a).

. Adequação do pré-natal e peso ao nascer: uma revisão sistemática. Cadernos de Saúde Pública, v. 20 , n. 5, p. 1160-1168, set.-out. 2004(b).

.; da COSTA J. S. D. Atenção pré-natal na rede básica: uma avaliação da estrutura e do processo. Cadernos de Saúde Pública, v. 17, n. 1, p. 131-139, jan.-fev. 2001.

SOCIEDADE BRASILEIRA DE PEDIATRIA - SBP. Infra-estrutura para atendimento integral do recém-nascido. Disponível em: < http://www.sbp.com.br/show_item2.cfm?id_categoria=21\&id_ detalhe $=16368$ tipo_detalhe $=\mathrm{s}>$. (Documento Científio do Departamento de neonatologia da Sociedade Brasileira de Pediatria, aprovado em reunião do Conselho Científico em 17/03/2004.).

THEME-FILHA, M. M.; SILVA, R. I.; NORONHA, C. P. Mortalidade materna no município do Rio de Janeiro, 1993 a 1996. Cadernos de Saúde Pública, v. 15, n. 2, p. 397-403, abr.-jun. 1999.

WORLD HEALTH ORGANIZATION - WHO. The world health report 2005: make every mother and child count. Geneva, Switzerland: World Health Organization, 2005. 